\title{
Northward Penetration of Antarctic Intermediate Water off Northwest Africa
}

\author{
F. MAChín AND J. L. Pelegrí \\ Institut de Ciències del Mar (CSIC), Barcelona, Spain
}

(Manuscript received 13 April 2007, in final form 1 September 2008)

\begin{abstract}
In this article, historical and climatological datasets are used to investigate the seasonal northward propagation of Antarctic Intermediate Waters (AAIW) along the eastern margin of the North Atlantic subtropical gyre. A cluster analysis for data north of $26^{\circ} \mathrm{N}$ shows the presence of a substantial number of hydrographic stations with AAIW characteristics that stretch northeast along the African slope. This water mass extends north during fall, as shown both through the comparison of actual and climatological data, and by applying a mixing analysis to normal-to-shore seasonal sections at both $28.5^{\circ}$ and $32^{\circ} \mathrm{N}$. The mixing analysis is further used with several fall cruises between $32^{\circ}$ and $36^{\circ} \mathrm{N}$, and shows that at these latitudes the core of AAIW propagates along the 27.5 isoneutral with contributions that reach as much as $50 \%$ at $32.5^{\circ} \mathrm{N}$. An idealized Sverdrup-type model is used in combination with climatological hydrographic and wind data to examine what forces this eastern boundary propagation. It is found that column stretching, initiated in the tropical North Atlantic, is the dominant term in the vorticity balance of the AAIW stratum, capable of sustaining a winter-spring-summer northward transport of about 3-4 Sv $\left(1 \mathrm{~Sv} \equiv 10^{6} \mathrm{~m}^{3} \mathrm{~s}^{-1}\right)$ that reaches as far north as the Canary Archipelago $\left(28^{\circ} \mathrm{N}\right)$. In fall, this transport may continue beyond $28^{\circ} \mathrm{N}$, sustained by a near-slope meridional stretching of this water stratum. AAIW probably fades away in the northeastern region as the result of several processes, specially enhanced double diffusion with surrounding waters and interaction with Mediterranean water lenses.
\end{abstract}

\section{Introduction}

The large-scale horizontal distributions of salinity, oxygen, and silica indicate that most Antarctic Intermediate Waters (AAIW) reach the eastern North Atlantic through the western boundary current system and its eastward extension by the Azores and North Atlantic Currents (Wüst 1935; Broecker and Takahashi 1981; Kawase and Sarmiento 1985; Tsuchiya 1989; Tsuchiya et al. 1992; Reid 1994; Lozier et al. 1995; Fratantoni et al. 2000). In these maps AAIW appears as a wedge of low salinity and high silica values originating at the Straits of Florida and stretching northeast in the 600$1100-\mathrm{m}$ water-depth range ( $\sigma_{\theta}$ range between 27.3 and 27.6), its depth (density) decreasing (increasing) with latitude. Some of these same maps also suggest a narrow northward penetration along the eastern margin, as the constant property lines stretch northeast along the Af-

Corresponding author address: F. Machín, Institut de Ciències del Mar (CSIC), Passeig Marítim de la Barceloneta, 37-49, 08003 Barcelona, Spain.

E-mail: fmachin@icm.csic.es rican coastline, but they are produced with rather low spatial resolution data that do not permit the identification of the spreading path (Kawase and Sarmiento 1985; Reid 1994; Lozier et al. 1995).

More detailed regional studies off northwest Africa have detected the presence of AAIW as far north as $20^{\circ}-25^{\circ} \mathrm{N}$ (Zenk et al. 1991; Tsuchiya et al. 1992; Stramma and Schott 1999; Fratantoni and Richardson 1999; Pérez et al. 2001; Stramma et al. 2005). Mittelstaedt (1983) described early the existence of a deep (centered at about $800 \mathrm{~m}$ ) poleward slope current and proposed that AAIW reaches as far north as the Canary Archipelago $\left(28^{\circ} \mathrm{N}\right)$, and Arhan et al. (1994) actually found AAIW off Cape Ghir $\left(31^{\circ} \mathrm{N}\right)$. Knoll et al. (2002) examined about two years of current meter data in the channel between the eastern Canary Islands and the African coast. They found a well-defined northward flow of AAIW at about $28.5^{\circ} \mathrm{N}$, with a mean velocity of $2.3 \pm 0.3 \mathrm{~cm} \mathrm{~s}^{-1}$, which intensified in fall. Machín et al. (2006) used four seasonal cruises to examine the distribution of water masses and the mass and nutrient fluxes north of the Canary Islands, in a $600 \mathrm{~km}$ band adjacent to the African coast. They observed the presence 
of low-salinity and high-silica waters near the African slope, centered at depths of $800 \mathrm{~m}\left(\sigma_{\theta} \cong 27.4\right)$, all year long at about $28.5^{\circ} \mathrm{N}$ and during fall also at $32^{\circ} \mathrm{N}$ (north of Cape Ghir). These distributions were consistent with the presence of intermediate northward slope currents during fall at both latitudes.

Regional modeling efforts have provided complementary, but sometimes contradictory, information. Paillet and Mercier (1997) used an inverse model for the eastern North Atlantic with $2500 \mathrm{~m}$ as a reference level and found no AAIW along the eastern boundary. Fratantoni et al. (2000) modeled the water pathways for the tropical Atlantic and found that intermediate waters continue north only along the western boundary. Other authors, however, have indeed found a clear signal of northward flow off the eastern boundary slope at intermediate depths. Batteen et al. (2000) used a regional model with flat bottom and climatological seasonal winds for the region between Cape Ghir and the Iberia Peninsula, and as far as $17^{\circ} \mathrm{W}$. They obtained a ubiquitous deep poleward undercurrent at several latitudes between Cape Ghir and the Iberian Peninsula, typically located between 1000- and 1400-m depths within $50 \mathrm{~km}$ from the shelf break. Batteen et al. (2007) used a similar domain to model the currents between March and September 1996 using daily winds and realistic bathymetry. They again found the deep undercurrent at similar depths and distances offshore but accompanied by a shallow (top $300 \mathrm{~m}$ ) poleward undercurrent nearshore. Johnson and Stevens (2000) ran a model for a similar region, but extending south of the Canary Islands and as far as $35^{\circ} \mathrm{W}$, forced by monthly mean winds. They show some snap distributions of current fields that display northward flow in the passages between the Canary Islands at intermediate depths, and low salinity values at these same depths at $32^{\circ} \mathrm{N}$. Elmoussaoui et al. (2005) used a much larger domain covering all the tropical and part of the subtropical ocean, as far as $60^{\circ} \mathrm{W}$ and $40^{\circ} \mathrm{N}$, forced by seasonal climatology and heat fluxes. These authors present some results that illustrate a preferential summer propagation of AAIW (as compared with winter) along $25^{\circ} \mathrm{W}$ and as far north as $28^{\circ} \mathrm{N}$ that appears to be associated to the presence of a deep poleward undercurrent.

The sparse observations and the above model results illustrate how little we know of the dynamics of this complex poleward system of eastern currents. What appears clear is that North Atlantic Central Waters (NACW) are characterized by the equatorward flowing Canary Current, which becomes intensified in the upwelling region (Pelegrí et al. 2005a), and that these waters also display a poleward undercurrent that flows adjacent to the slope, typically centered at 200 or $300 \mathrm{~m}$ but occa- sionally surfacing (Barton 1989). This poleward undercurrent may have meridional continuity from the tropical region to the Iberian Peninsula, possibly carrying South Atlantic Central Waters (SACW; Pelegrí et al. 2006). Deeper and further offshore, typically centered at some $1000 \mathrm{~m}$ and $100 \mathrm{~km}$ off the slope, we find the deep poleward undercurrent, with its load of low-salinity AAIW waters. These two poleward undercurrents usually appear clearly separated in two different cores, although in some instances they may barely join to give the impression of a large and coherent region of poleward flow.

When the two poleward undercurrents reach the Canary Archipelago the situation gets even more complex, as they encounter the southward-flowing NACW, which is intensified by the Archipelago channeling effect. During most of the year, NACW progresses south through the eastern channels but from late summer to early winter the main southward flow is displaced west (Hernández-Guerra et al. 2001, 2003; Navarro-Pérez and Barton 2001). This is likely the consequence of the flow intensification following the strong summer winds: the Canary Current becomes unstable near Cape Ghir and moves several hundred kilometers offshore producing a large cyclonic loop that embraces the Canary Archipelago (Pelegrí et al. 2005a,b). This makes the near-surface poleward undercurrent surface and flow north along the eastern Canary Archipelago channels (Hernández-Guerra et al. 2001, 2003). One would expect the deep poleward undercurrent to not be affected by this flow inversion but we will see that this water mass also experiences its maximum northward propagation during fall. The connection occurs as the fall cyclonic loop south of the Canary Islands raises the upper-thermocline layers, which stretches the AAIW column and bolsters the northward flow of this water mass.

Figure 1 has been produced using data from the World Ocean Database 2001 (see the next section). It shows the salinity, neutral density, and dissolved oxygen distributions for a meridional section along a hypothetic track for AAIW, along $19^{\circ} \mathrm{W}$ until $20^{\circ} \mathrm{N}$ and then northeast (NE) approximately parallel to the coast, from the equatorial region to near the Strait of Gibraltar. The isohalines in the top panel illustrate the presence of lowsalinity and low-oxygen AAIW, which stretches north initially centered at about the 27.4 neutral density surface but increasing in density with latitude until it levels at about 27.55 near $25^{\circ} \mathrm{N}$. Nevertheless, oxygen is minimum at the SACW neutral levels south of Cape Verde (roughly at $16^{\circ} \mathrm{N}$ ), as a result of the long times these waters spend within Pedlosky (1983)'s shadow zone. The lower panel displays the shape of the isoneutrals, with a local maximum in the depth of central waters (down to 27.2) occurring near $22^{\circ} \mathrm{N}$. The isoneutrals that 


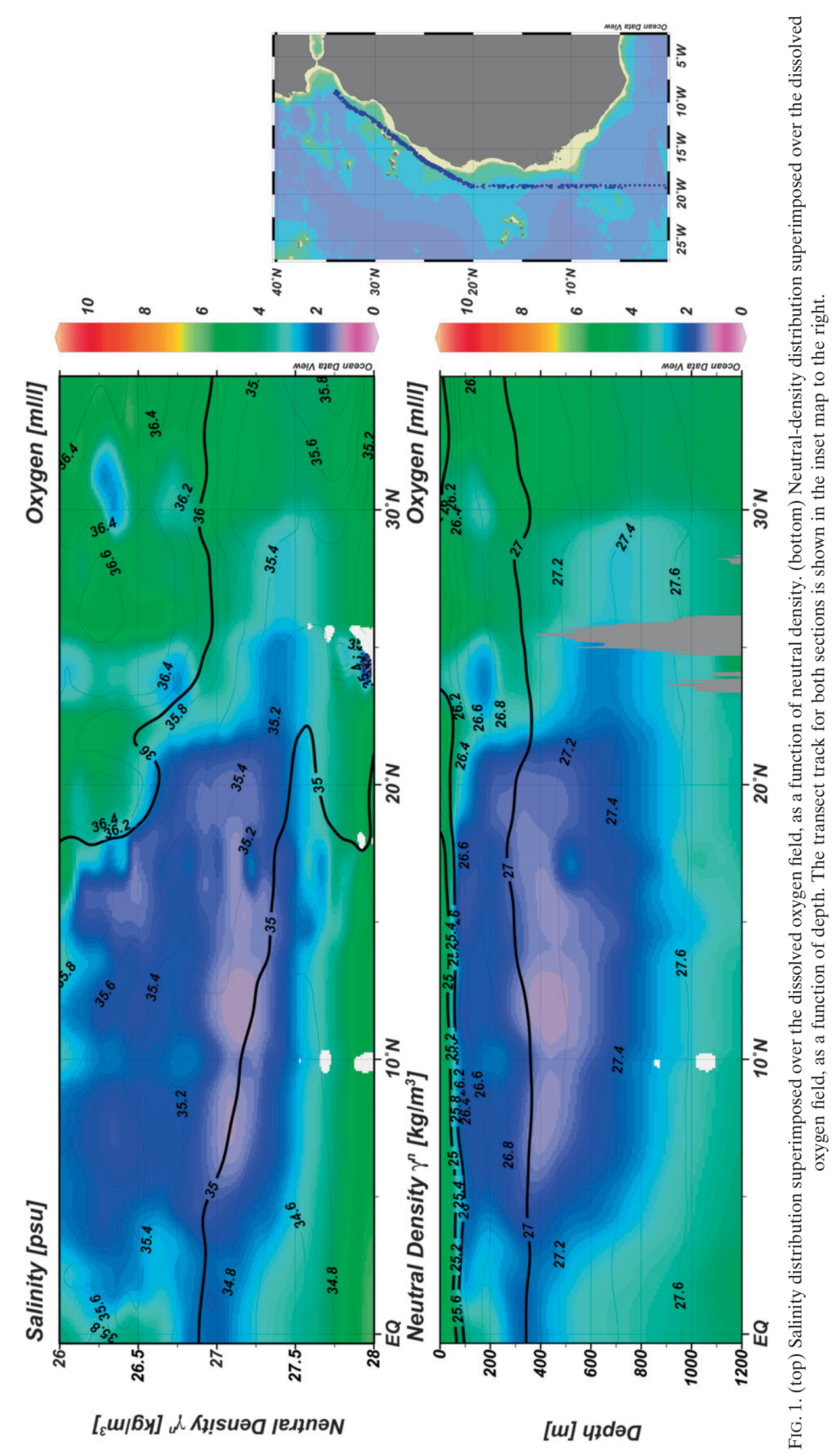


would define the AAIW, however, only rise north of the Canary Islands (beyond $30^{\circ} \mathrm{N}$ ).

In this article we examine several datasets for the area (section 2). We first make an analysis of historical sections for the whole Canary Basin and cluster them in groups that characterize AAIW, Mediterranean Water (MW), and NACW (section 3). In section 4 we use climatological data plus four cruises at both $28.5^{\circ}$ and $32^{\circ} \mathrm{N}$ to explore the seasonal meridional penetration of AAIW as far north as Cape Ghir $\left(31^{\circ} \mathrm{N}\right)$. This confirms that maximum northward spreading occurs in fall, so we move to examine four fall and one winter hydrographic cruises carried out along the African slope, in the region between the Canary Islands and the Strait of Gibraltar, to explore the path and extension of fall's AAIW spreading north of $32^{\circ} \mathrm{N}$ (section 5). In section 6 we present an idealized model, which, used in conjunction with climatological data, suggests that meridional spreading results from a seasonal evolution of the thickness of the AAIW layer in the eastern boundary, as stretching of this layer progresses north from tropical to subtropical waters. In section 7 we briefly consider what might be the outcome of the northward propagating AAIW, and sum up with the conclusions in section 8 .

\section{Dataset}

To investigate the spreading of AAIW along the eastern North Atlantic we use four different datasets. First, in order to describe the distribution of hydrographic properties (sections 1, 6, and 7) we use both an ocean climatology, the World Ocean Atlas 2001 (WOA01), and two oceanographic databases, the World Ocean Database 2001 (WOD01) and Hydrobase-2. In section 6 we also use the climatological wind stress as obtained from the Southampton Oceanographic Center (SOC) database. The WOAO1 and SOC climatologies have $1^{\circ}$ latitude by $1^{\circ}$ longitude horizontal resolution, with hydrographic data given at standard oceanographic depths.

Second, we searched through the ocean databases for data in the area that goes from $26^{\circ}$ to $38^{\circ} \mathrm{N}$ and from the African and Iberian Peninsula coast to $29^{\circ} \mathrm{W}$. Most of these data have been obtained from the Hydrobase- 2 and Canary Islands Azores Gibraltar Observations (CANIGO; Parrilla et al. 2002a,b) databases, complemented with hydrographic cruises carried on in the area by the Institut für Meereskunde at Kiel and the Universidad de Las Palmas de Gran Canaria (R/V Ignat Pauvlynchenkov 1991; BIO Hespérides 1993, 1995, and summer 1997; R/V Poseidon cruise P202). In section 3, we use the whole dataset to perform a cluster analysis to characterize the region of eastern AAIW propagation.

A third dataset is the easternmost portion (from approximately $14^{\circ} \mathrm{W}$ to the African shelf) of four normal-
TABLE 1. Hydrographic cruises used to examine spreading of AAIW along the African continental slope. A16B, C and D are named following the WOCE notation.

\begin{tabular}{lcl}
\hline \multicolumn{1}{c}{ Cruise } & \multicolumn{1}{c}{ Dates } & Description \\
\hline F91(A16B) & 10-22 Sep 1991 & Radials \\
W92 (A16C) & 15-17 Jan 1992 & Along-shore \\
F92 (A16D) & 16-21 Sep 1992 & Radials \\
F95 (Hespérides 95) & 5-10 Oct 1995 & Along-shore \\
F97 (Hespérides 97) & 27 Sep-1 Oct 1997 & Along-shore \\
\hline
\end{tabular}

to-shore cruises carried out at $28.5^{\circ}$ and $32^{\circ} \mathrm{N}$, one per season. In section 4 we use these data to investigate AAIW's seasonality in the region and conclude that maximum AAIW northward penetration occurs in fall.

In section 5 we use the fourth dataset, which consists of five cruises (four during fall and one in winter) carried out near the African coast in the northern region, between the Strait of Gibraltar and the Canary Islands (Table 1; Fig. 2). Cruises A16B, A16C, and A16D are World Ocean Circulation Experiment (WOCE) repeat Atlantic sections that have been obtained from the WOCE Global Data Resource service. During the A16B cruise, carried out in fall 1991 (hereafter F91), five radial lines occupied the coastal transition zone between $32^{\circ} \mathrm{N}$ and the Gulf of Cádiz. The A16D cruise was done in fall 1992 (hereafter F92) and had four radial lines at similar locations to F91. Cruise A16C, carried out during winter 1991-92 (hereafter W92), was quite different, with a section parallel to the African coast approximately along the 2000-m isobath. In these three cruises all CTD casts reached down to at least $2000 \mathrm{~m}$ depths. The remaining two cruises were done during fall 1995 and 1997 (hereafter F95 and F97, respectively) by the Universidad de Las Palmas de Gran Canaria (Pelegrí et al. 2005b). They consist of sections running along the continental slope, as in W92, though CTD casts reached down to only $1000 \mathrm{~m}$.

Finally, in section 7 we use data from a mooring deployed as part of the European Station for Time Series in the Ocean Canary Islands (ESTOC). Velocity, temperature, and salinity time series were monitored at ESTOC (Fig. 2) from September 1994 to September 1997 (data available online at www.pangea.de). The current meters' temperature and salinity data were recalibrated with CTD data taken during each mooring deployment cruise. Current meter data were low-pass filtered with a cutoff period of $40 \mathrm{~h}$ to eliminate tidal and inertial signatures from the time series.

\section{AAIW path off northwest Africa}

Our first task is to investigate where AAIW is most commonly found, with the idea that this will tell us its 

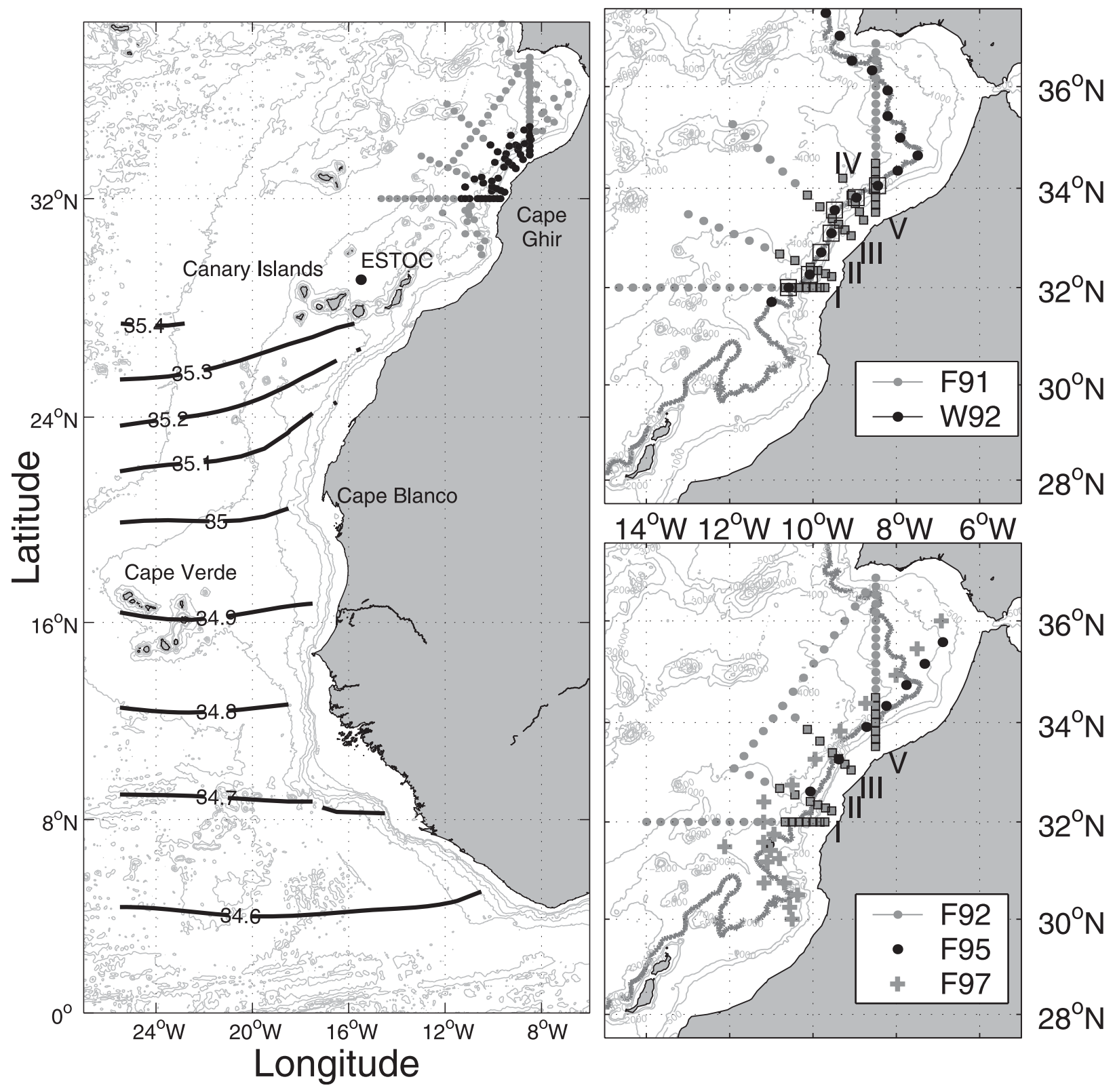

FIG. 2. (left) Area under study with gray dots indicating all hydrographic stations and the black dots representing those sections employed to examine the fall propagation of AAIW along the African coast. The annual climatological salinity on the 27.5 isoneutral density is contoured in the tropical and subtropical region. (right) Stations during the (upper) F91 and W91 and (lower) F92, F95, and F97 cruises. Squared dots indicate the stations used in this study, extracted from a wider database (dots). The cross-shore radials mentioned in the text are numbered.

propagation path. With this purpose we have done a simple analysis that defines some reference temperature $T$ and salinity $S$ values for the upper and intermediate water masses within certain depth range, and have grouped stations in a predetermined number of clusters according to their proximity to these reference values.
The temperature and salinity reference values $\left(T_{r}, S_{r}\right)$ in the 500-760-m-depth range are $(13.00,35.80)$ for NACW, $(8.30,35.23)$ for AAIW, and $(11.70,36.00)$ for MW. Those are slightly different than AAIW and MW reference values at their respective cores, because we are working at shallower depths here, but are deep enough to distinguish those waters influenced by AAIW 

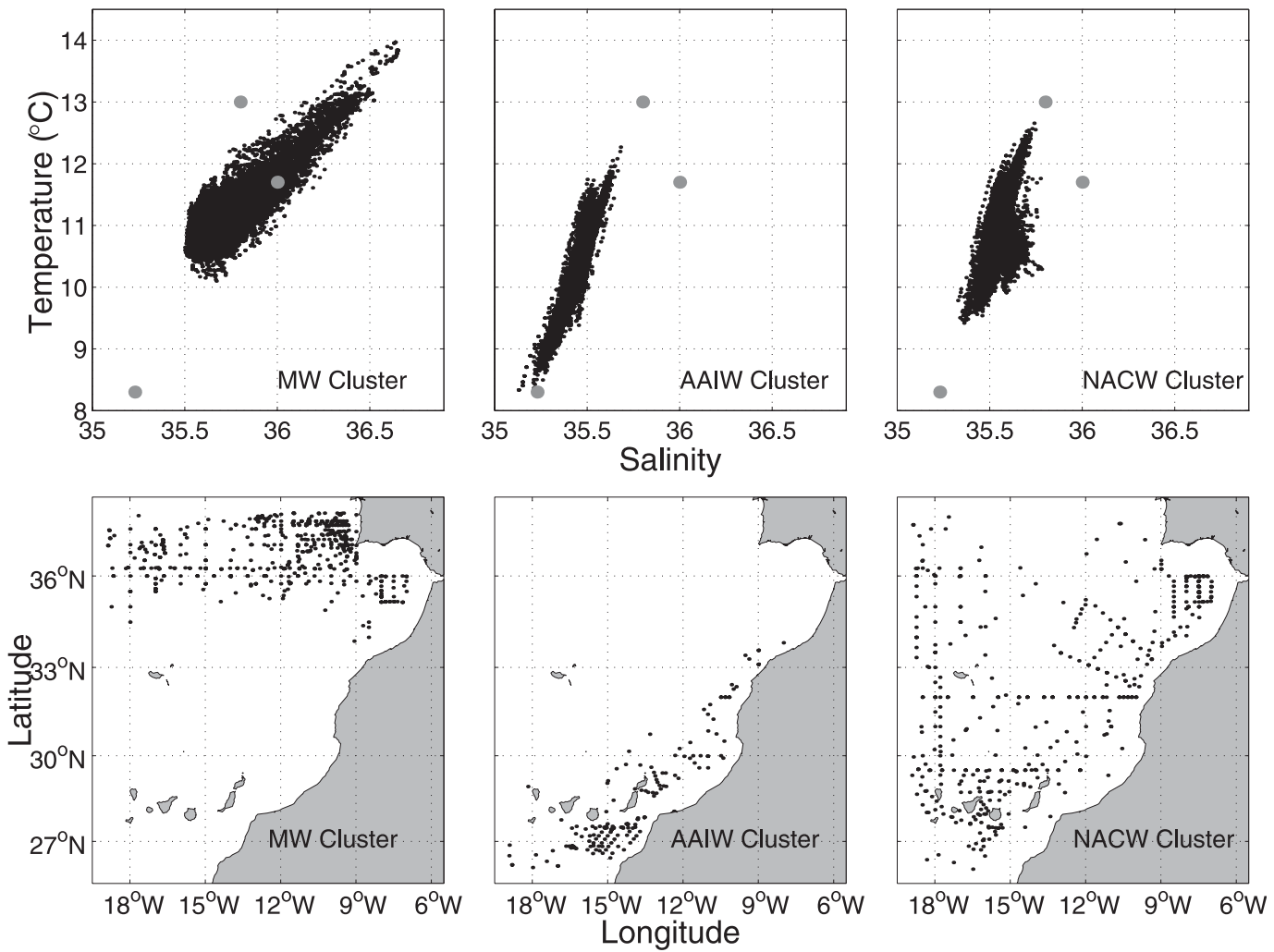

FIG. 3. (top) The $T-S$ observations and (bottom) stations assigned to (left) MW, (center) AAIW, and (right) NACW clusters. Gray dots in the upper panels indicate the reference values.

or MW. We define a weighted distance to the reference points in the $T-S$ space as follows:

$$
d\left[(T, S),\left(T_{r}, S_{r}\right)\right]=\left[\left(T-T_{r}\right)^{2}+\phi\left(S-S_{r}\right)^{2}\right]^{1 / 2},
$$

where $\phi$ is a factor used to give equivalent weights to temperature and salinity differences. This factor is chosen to be $\phi=6$, simply calculated as the fraction of the temperature and salinity ranges for the data in the 500-to-760-m-depth range. Specifically, temperature ranges from $8^{\circ}$ to $14^{\circ} \mathrm{C}$, while salinity does from 35.3 to 36.3 , so salinity needs to be multiplied by a factor of six to have the same weight as temperature when evaluating a distance in the temperature-salinity domain.

We use Eq. (1) to compute the (weighted) distance $d$ for all $(T, S)$ points in the 500-to-760-m-depth range. The total distance $D$ between one profile and each water mass reference value is then simply calculated as a normalized summation of all these distances. In this manner for each profile we have three different total distances $\left(D_{\mathrm{NACW}}, D_{\mathrm{AAIW}}\right.$, and $\left.D_{\mathrm{MW}}\right)$, and the station belongs to the cluster with the smallest $D$. The top panels of Fig. 3 show the $T-S$ diagrams for all data points corresponding to these three clusters. We may see that MW/AAIW clusters display characteristic high/ low salinity and temperature waters, while the NACW cluster corresponds to points of intermediate temperature and salinity values.

The bottom panels of Fig. 3 display the location of the corresponding stations for each cluster. We may see that the MW stations stretch west of Gibraltar and north along the coast of the Iberian Peninsula, in agreement with the propagation patterns discussed by Iorga and Lozier (1999). The AAIW stations, on the other hand, remain exclusively along the African coast, decreasing in number with latitude. As far north as Cape Ghir $\left(31^{\circ} \mathrm{N}\right)$ we find AAIW to dominate but farther north it is rapidly replaced by NACW and MW. Finally, the distribution of the NACW stations shows that this is the dominant water mass at the analyzed depth range, as they are found rather evenly distributed throughout the region.

\section{Seasonal penetration up to Cape Ghir}

Once we have established that the path for AAIW is along the African slope, we wish to determine whether its northward penetration is enhanced during some particular season. The dominance of the AAIW cluster 


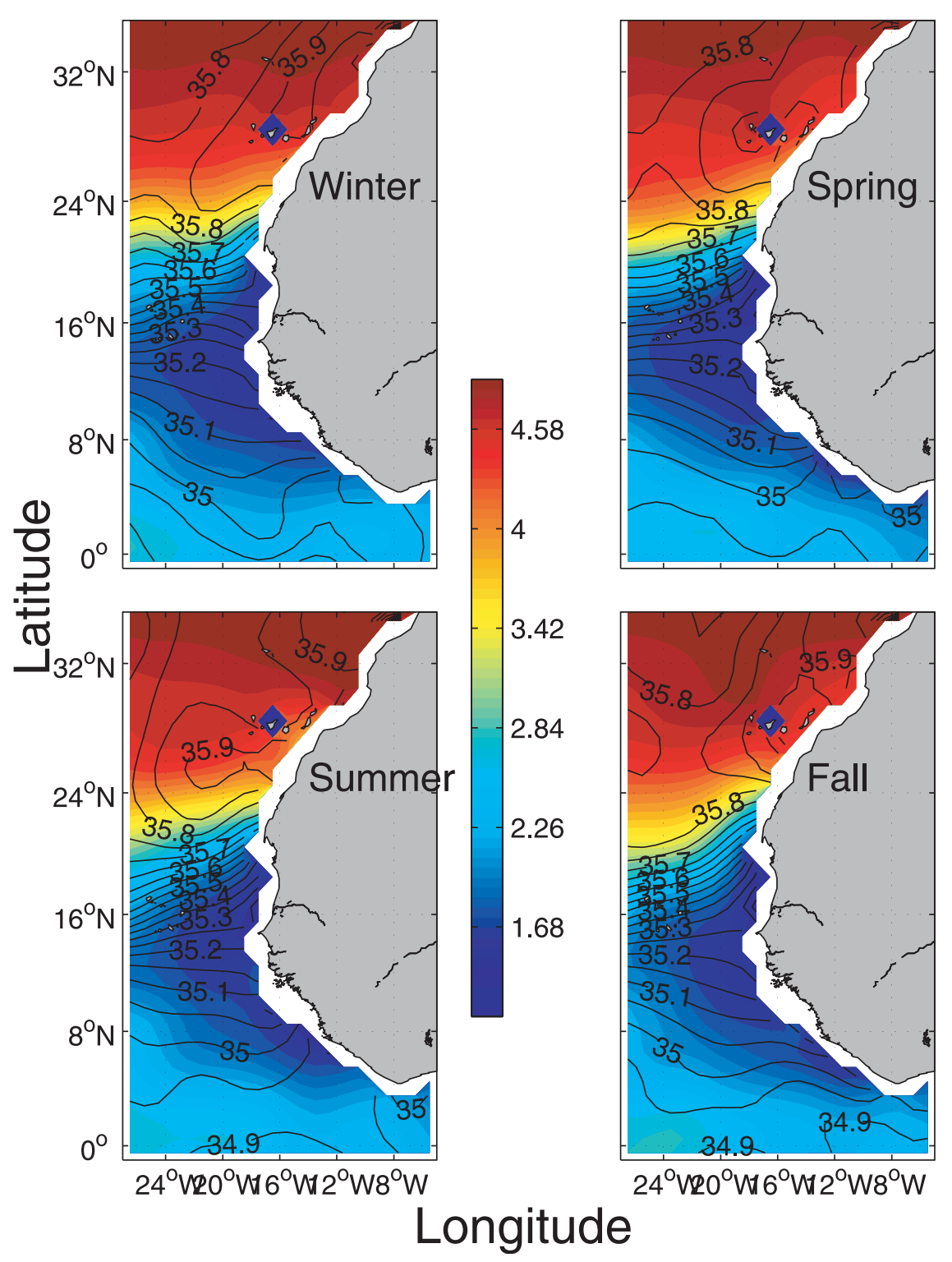

FIG. 4. Seasonal salinity and dissolved-oxygen distributions on isoneutral surface $\gamma_{n}=27.0$, from WOA01 database.

as far north as Cape Ghir suggests that its signal may also appear in the climatological seasonal data. Therefore, we have first examined the WOAO1 seasonal distributions of salinity and dissolved oxygen on two isoneutral surfaces, 27.0 and 27.5 (Figs. 4 and 5), which respectively characterize the central and intermediate water strata. These data has low spatial resolution $\left(1^{\circ}\right.$ latitude by $1^{\circ}$ longitude), which causes very poor coverage of the slope region, but still provides some interesting information. The 27.0 distributions (Fig. 4) display substantial meridional gradients in salinity, with maximum changes near the Cape Verde frontal zone [roughly stretching along the NE-southwest (SW) axis between Cape Blanc and the Cape Verde Islands], that are characteristic of the transition from SACW to NACW. South of this front the isohalines are nearly zonal, but north of the front they tilt, roughly parallel to it, which indicates their northern and southern origins. An isolated oxygen minimum clearly appears south of this frontal zone but reaches south only until about $5^{\circ} \mathrm{N}$, which is suggestive of the long residence times in the shadow zone of the North Atlantic thermocline circulation. The maximum northward penetration of this oxygen minimum appears to take place in fall, in 


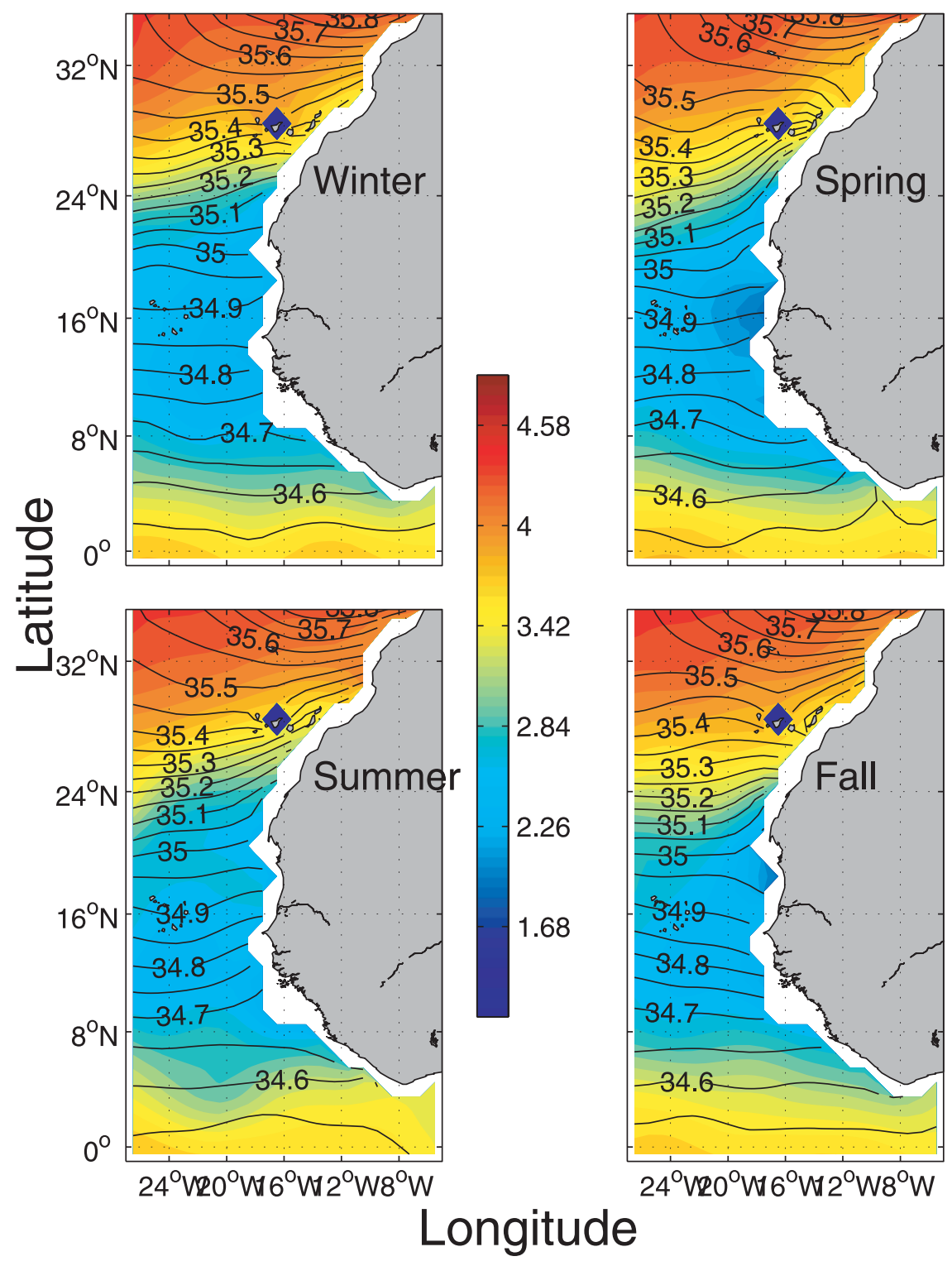

FIG. 5. Seasonal salinity and dissolved-oxygen distributions on isoneutral surface $\gamma_{n}=27.5$, from WOA01 database.

agreement with observations of flow reversals in the eastern Canary Islands and probably associated to the intensification of the shallow poleward undercurrent (Hernández-Guerra et al. 2001, 2003; Navarro-Pérez and Barton 2001).

The 27.5 distributions (Fig. 5) also show meridional gradients in salinity but, as expected for intermediate water, there is no intensification associated with the Cape Verde frontal zone. The isohalines do not change greatly between seasons but there is some along-slope northward progression of low-salinity waters between spring and summer. The oxygen distribution also ex- hibits an eastern boundary smooth minimum, roughly between $10^{\circ}$ and $22^{\circ} \mathrm{N}$. The southern limit of this region is an artifact caused by AAIW being less dense in the equatorial region (Fig. 1), but the northern penetration of AAIW may indeed be related to these salinity and oxygen distributions. During spring and summer both isohalines and iso-oxygen lines do stretch northeast along the slope, suggesting, as in central waters, a northward flow in this water stratum. The northward propagation of the $S<35.4$ isoline may be observed to occur from spring, when it reaches the Canary Islands, to summer and fall, when this isoline extends well 


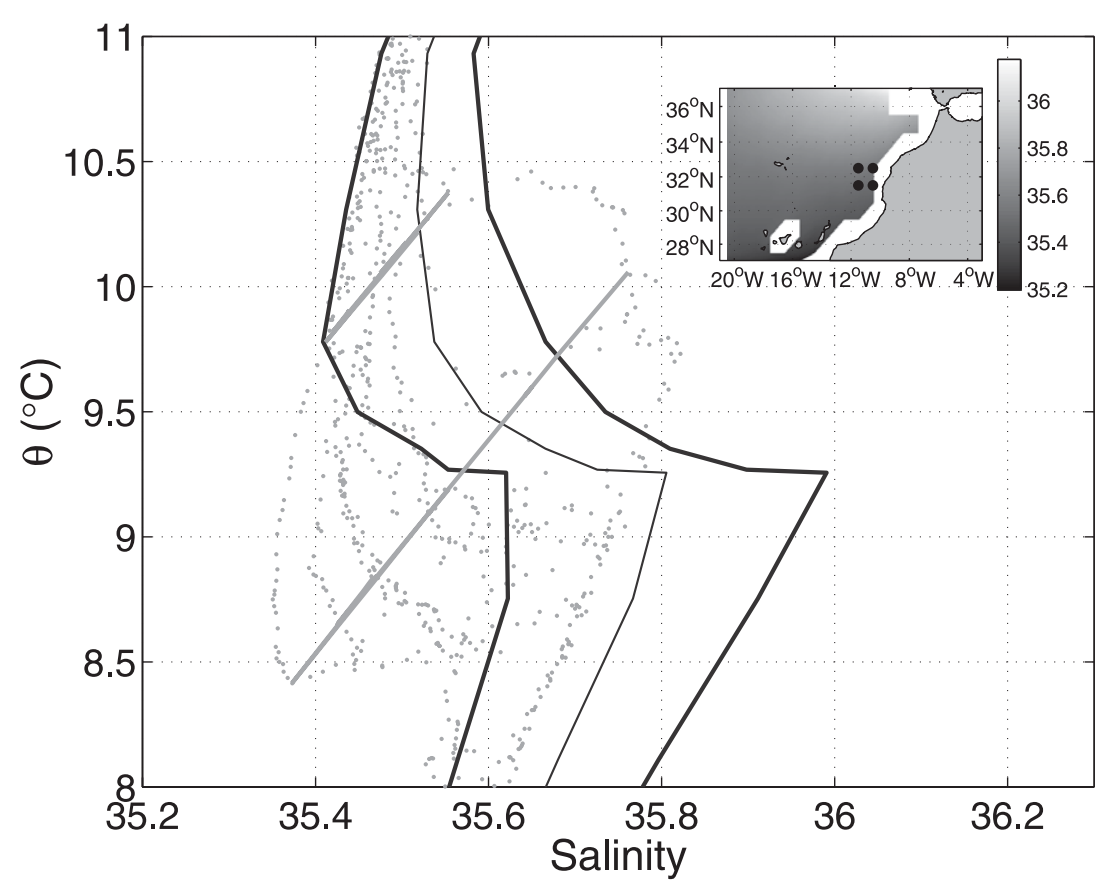

FIG. 6. Mean and three-standard deviation $T-S$ diagrams (black solid lines) produced with the annual-mean climatological data for the area from $10^{\circ}$ to $12^{\circ} \mathrm{W}$ and from $31^{\circ}$ to $33^{\circ} \mathrm{N}$ (see inset), with the 27.4 and 27.6 isoneutrals (gray solid lines). The data points for the fall cruises in this same area are included to illustrate their relative low salinity values.

beyond the Canary Islands along the slope. A striking feature is the intensification of the oxygen minima at about $16^{\circ} \mathrm{N}$ in spring and, more weakly, in summer and fall at about $19^{\circ} \mathrm{N}$. We will see later that these minima are probably related to the seasonal shallowing of this isoneutral.

We follow a simple procedure to appreciate the significance of the fall propagation. The annual-mean climatological data for the area from $10^{\circ}$ to $12^{\circ} \mathrm{W}$ and from $31^{\circ}$ to $33^{\circ} \mathrm{N}$ is used to define a $T-S$ domain that characterizes the mean conditions (Fig. 6). This is the domain encompassed by the 27.4 and 27.6 isoneutrals and by the curves corresponding to three standard deviations beyond the mean $T-S$ curve. On top of this diagram we have plotted all data points from our fall cruises that belong to this geographical region. We find that most of these data points $(59 \%)$ have low salinities that fall out of the meancondition $T-S$ domain.

To further examine the AAIW seasonal penetration we have also reanalyzed the eastern portion of four seasonal normal-to-shore cruises at $28.5^{\circ}$ and $32^{\circ} \mathrm{N}$, discussed by Machín et al. (2006) (Fig. 7). In these sections we carry out a water-mass mixing analysis as described in, for example, Castro et al. (1998). The method assumes linear mixing between three water types, with no exchange at the sea surface, to produce the actual temperature and salinity observations:

$$
\begin{aligned}
x_{1} T_{1}+x_{2} T_{2}+x_{3} T_{3} & =T, \\
x_{1} S_{1}+x_{2} S_{2}+x_{3} S_{3} & =S, \\
x_{1}+x_{2}+x_{3} & =1,
\end{aligned}
$$

where $x_{i}$ are the fractions of each water type contributing to a given temperature $T$ and salinity $S$ observation, and $T_{i}$ and $S_{i}$ are the temperature and salinity values that characterize each water type. The first two equations represent the temperature and salinity mixing of the three water types, and the third equation indicates that their joint contribution equals one.

The linear system (2) determines the contribution from as many as three water types to a given sample. To obtain the contribution from four water types [NACW, AAIW, MW, and North Atlantic Deep Water (NADW)] we have to introduce a criterion to separate them in groups of three. A plausible assumption is that NACW and NADW never contribute to the same observation so the groups are, in the upper layers, NACW, AAIW, and MW, and, in the lower layers, AAIW, MW, and NADW. The separation level between these two groupings is calculated objectively by examining the existing water types at $0.01 \gamma_{n}$ intervals. We observed that at 27.6 no NACW was present, so we set this neutral density as the transition level.

The results are presented in Fig. 7. To best represent the relative contribution of all water types in one same 

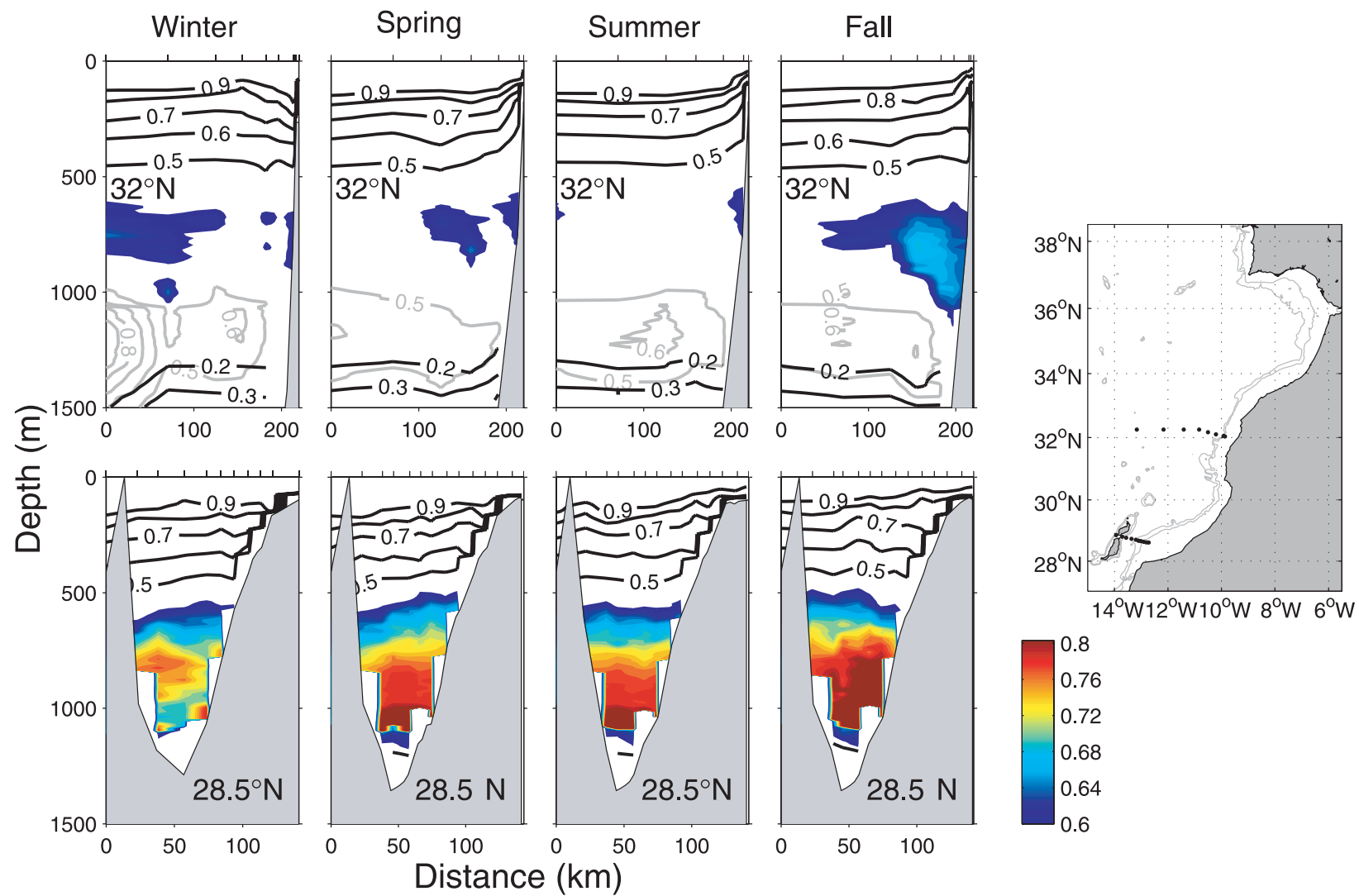

FIG. 7. AAIW contribution to observations during the CANIGO (bottom) $28.5^{\circ} \mathrm{N}$ and (top) $32^{\circ} \mathrm{N}$ cruises, as shown in the rhs map. AAIW contributions above $60 \%$ are colored according to the rhs scale. Solid lines represent the contributions of NACW, MW, and NADW, with $10 \%$ contribution intervals. Dark isolines in the top $500 \mathrm{~m}$ indicate NACW contributions above $60 \%$, gray isolines at intermediate levels $(800-1300 \mathrm{~m})$ indicate the MW contribution, and dark isolines at greater depths indicate the presence of NADW; 500 and $1000 \mathrm{~m}$ isobaths are indicated in the map.

figure, the AAIW contribution is in color for concentrations above $60 \%$, while the NACW, MW, and NADW contributions are contoured. NACW and MW isolines are contoured where their contribution is above $50 \%$, while the NADW isolines are drawn when its contribution is higher than $20 \%$. At $28.5^{\circ} \mathrm{N}$ we find that AAIW dominates all year long in the channel between the Canary Islands and the African slope between 600 and $1200 \mathrm{~m}$. Seasonal differences are relatively small, the maximum AAIW contribution occurring in fall with its core close to the African slope. At $32^{\circ} \mathrm{N}$ the result is very different, as AAIW is dominant only in fall, in the 750-to-800-m-depth range and within $150 \mathrm{~km}$ of the African slope. During winter, a substantial fraction of AAIW persists but it is found disconnected from the continental slope and in lower concentrations, while for spring and summer the AAIW contribution decreases.

\section{Fall spreading north of Cape Ghir}

As AAIW appears to find its maximum northward spreading during fall we decided to examine the com- position of intermediate waters north of the Canary Islands using hydrographic cruises carried out during this season. For this purpose we have selected four fall cruises (F91, F92, F95, and F97, as described in section 2), and examined the CTD stations indicated by squared dots in Fig. 2 (located approximately within $150 \mathrm{~km}$ offshore). For comparative purposes we have also examined one winter cruise (W92) that covers a similar area and was carried out only four months after F91 (Table 1).

Figure 8 shows a close up of the $T-S$ diagrams for all these stations. The upper $T-S$ diagrams correspond to F91 and W92, while the lower ones are for F92, F95, and F97. For reference, on these diagrams we superimpose the AAIW temperature and salinity conditions at $28.5^{\circ}$ and $32^{\circ} \mathrm{N}$ as documented by Machín et al. (2006). As the main core of the AAIW is located at about $\sigma_{\theta}=27.5$ (Zenk et al. 1991; Fiekas et al. 1992; Tsuchiya et al. 1992), we contour this isopycnal over the diagrams. During F91, a minimum in salinity is found on $\sigma_{\theta}=27.5$ at radials I, II, and III. During F92, the minimum is again observed at the southern radials I and II, along 


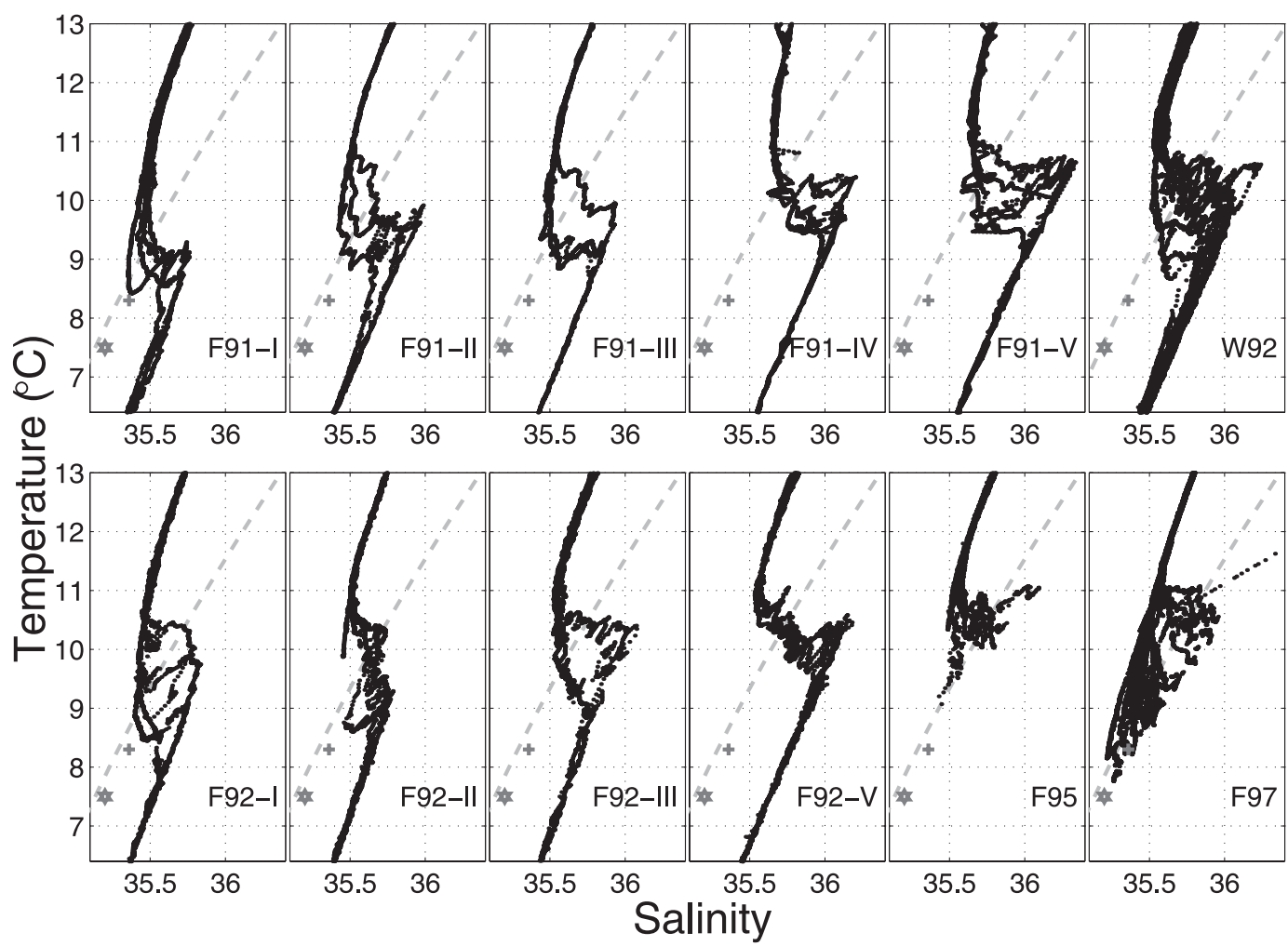

FIG. 8. The $T-S$ diagrams during the F91, F92, W92, F95, and F97 cruises. The isopycnal $\sigma_{\theta}=27.5$ is superimposed as a gray dashed line. The star and cross indicate the fall AAIW conditions at $28.5^{\circ}$ and $32^{\circ} \mathrm{N}$, respectively (Machín et al. 2006).

this same potential-density level. During W92, the salinity minimum is again visible near this isopycnal in the southern sections. During F95 and F97, sampling only reached down to $1000 \mathrm{~m}$ so the density range in the corresponding diagrams is reduced. Nevertheless, we note the presence of AAIW, particularly during F97.

In Fig. 9 we have plotted the contribution of all water types, following the same notation as in Fig. 7, in all normal-to-shore transects. NACW dominates in the upper ocean along the whole dataset, with values from $100 \%$ at the sea surface to $40 \%-50 \%$ at $500 \mathrm{~m}$. Similarly, NADW is always present below $1300 \mathrm{~m}(10 \%-20 \%)$, and MW is observed in all radials between 750 and $1500 \mathrm{~m}$ depth (in some northern locations contributing more than $50 \%$ ). AAIW is the water mass which shows the highest temporal and spatial variability. It is present in the 500 to $1000 \mathrm{~m}$ depth range in sections I, II, and III during the F91 cruise, its core close to the continental slope and contributing up to the $80 \%$ in radials I and II. During F92, we find most AAIW in radials I and II, its maximum contribution (nearly $70 \%$ ) being close to the continental slope and centered at $900 \mathrm{~m}$ along radial I.

Figure 10 shows the AAIW distributions as a function of $\gamma_{n}$ and latitude. For the along-slope sections (F95,
F97) we use only those stations located near the 2000-m isobath, while for those cruises with normal-to-shore sections (W92, F91, F92) we consider those stations closest to the AAIW core. During F91, a signal of AAIW is observed from $32^{\circ}$ to $33.5^{\circ} \mathrm{N}$ centered at a $\gamma_{n} \simeq 27.5$, with high concentrations in the $27.4 \leq \gamma_{n} \leq 27.6$ range but reaching as shallow as $\gamma_{n}=27.25$. During this cruise some MW is visible in the two northernmost stations, at about $34^{\circ} \mathrm{N}$. During F92 we find AAIW in the same density range as during F91, though a small fraction reaches as far north as $33^{\circ} \mathrm{N}$ on $\gamma_{n}=27.3$. For this cruise MW is again present near $34^{\circ} \mathrm{N}$. During W92 there is a substantial amount of MW between $32^{\circ}$ and $34^{\circ} \mathrm{N}$, in the $27.6 \leq \gamma_{n} \leq 27.8$ range, but AAIW is nearly absent. Finally, during F95 and F97, we find two situations that resemble those occurring during F91 and F92. In particular, the F97 distribution again shows that most AAIW propagates north in the $27.4 \leq \gamma_{n} \leq 27.6$ range.

\section{Idealized model}

So far we have seen that AAIW shows up north of the Canary Islands (between about 600 and $1100 \mathrm{~m}$ ) most 

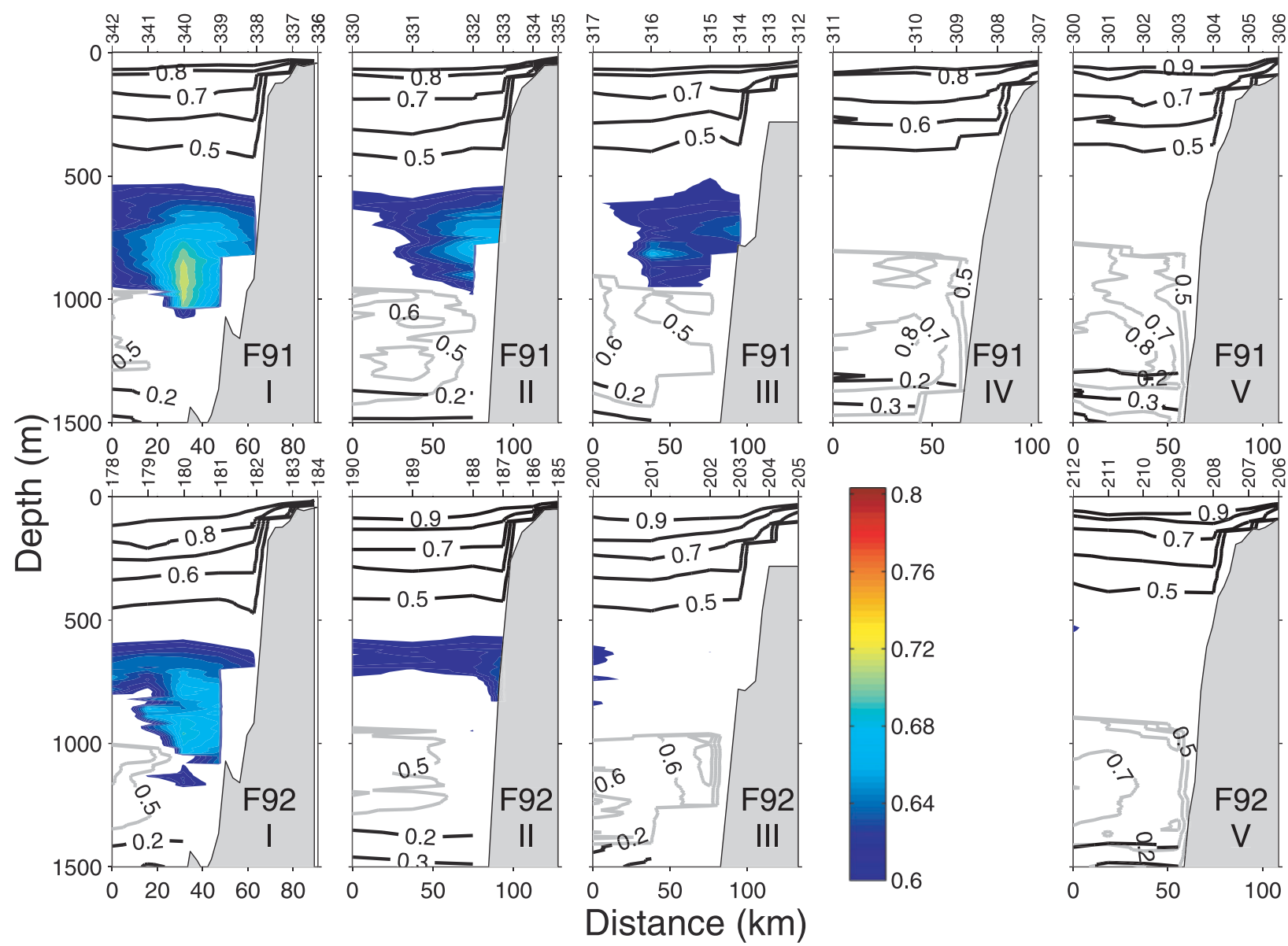

FIG. 9. AAIW contribution to observations in the normal-to-shore (upper) F91 and (lower) F92 radials. Legend as in Fig. 7.

clearly in fall. In this section we use an idealized model to pursue the idea that the seasonal propagation of AAIW is associated with the stretching of this watermass stratum initiated remotely in the eastern tropical ocean. The cyclonic current system in the North Atlantic tropical ocean is persistent all year long, but its extension and intensity changes seasonally as a result of variations in Ekman pumping in the tropical ocean off northwest (NW) Africa (Longhurst 1993; Signorini et al. 1999). During winter and spring this pumping region decreases in size but intensifies, with its maximum located right at the coast (Richardson and Walsh 1986; Peterson and Stramma 1991; Siedler et al. 1992; McClain and Firestone 1993). This causes local stretching; that is, the isoneutrals that constitute the top of the AAIW raise several tens of meters toward the sea surface and the thickness of the intermediate water stratum increases, inducing its northward propagation to maintain potential vorticity.

Figure 11 shows the spatial distribution of the temporal changes in depth of the $\gamma_{n}=27.3$, which is taken to characterize the upper limit of the AAIW in the tropical region. These changes are calculated over threemonth periods centered in February (winter), May (spring), August (summer), and November (fall). Negative values (dashed lines) correspond to shallowing of the interface isoneutral; that is, to the thickening of the AAIW stratum. In this figure we may appreciate a northward progression of the region characterized by the low salinity and dissolved-oxygen values (Figs. 1 and $5)$ : the water thickens in the tropical Guinea Dome region $\left(6^{\circ}-15^{\circ} \mathrm{N}\right)$ in winter, in the low-latitude subtropical band $\left(16^{\circ}-23^{\circ} \mathrm{N}\right)$ in fall, and in the high-latitude subtropical region $\left(24^{\circ}-29^{\circ} \mathrm{N}\right)$ in summer.

Additionally, there may be both advective stretchingshrinking and dianeutral mixing. A water column is stretched, for example, when it moves to a place where its thickness increases. This requires horizontal motions induced through another mechanism, such as local stretching. Turbulence in the uppermost layers may cause net exchange through isoneutrals (dianeutral mixing) in the upper and intermediate layers. The source of this 

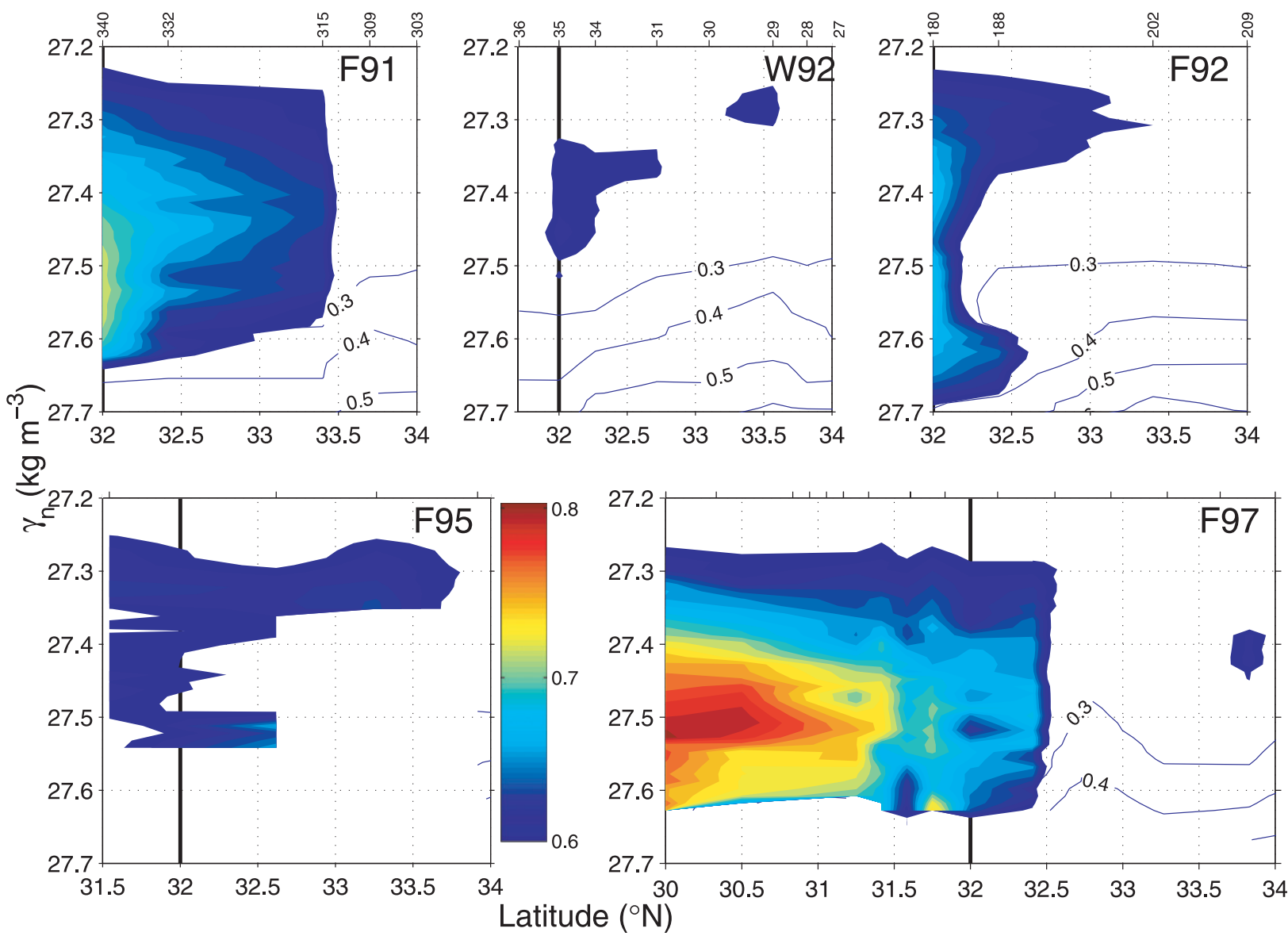

FIG. 10. Along-slope AAIW contribution as a function of neutral density $\gamma_{n}$ and latitude. As a reference, we draw the $32^{\circ} \mathrm{N}$ latitude as a vertical solid line. Isolines indicate the contribution of MW to observations in the region.

turbulence may be quite diverse, from barotropic and baroclinic upper-ocean motions, to direct wind stirring, among others.

To examine the origin of the AAIW meridional motions let us consider a Sverdrup-type model. Conservation of potential vorticity tells us that, in the Northern Hemisphere, a stretching column will flow north, and the opposite will occur when it shrinks. The model envisions stretching or shrinking AAIW material columns as the result of local-spatial changes in the depth of its overlying isoneutrals, and dianeutral transfer through these isoneutrals. Preferential dianeutral transfer (entrainment) into the upper layers will always tend to stretch the intermediate water columns, but the seasonal oscillation of the upper-ocean isoneutrals will induce a periodic stretching-shrinking effect of the underlying intermediate water stratum. For this idealized model (Fig. 12), we place the upper limit of AAIW at $\gamma_{n}=27.3$.

The potential vorticity model shares the same dynamics as classical models for the ventilated thermo- cline in the subtropical gyre (Luyten et al. 1983) and its extension for the subtropical cell in the tropical-equatorial region (Pedlosky 1987), but we will use it in its simplest form to calculate transports rather than trajectories. The main singularity of the model is its application to an AAIW stratum that does not outcrop. Schmid et al. (2000) did use this type of approach to examine the circulation of AAIW in the South Atlantic, forced through Ekman pumping from the surface mixed-layer, but to our knowledge this approximation has not yet been applied to study the propagation of an unventilated intermediate stratum as usually these waters are located quite deep. In the tropical region, however, the AAIW stratum gets shallow enough to become affected by processes in the upper thermocline, particularly by the seasonal vertical displacements of its upper-bounding isoneutrals.

The vorticity equation is

$$
\beta v=f \frac{\partial w}{\partial z}
$$




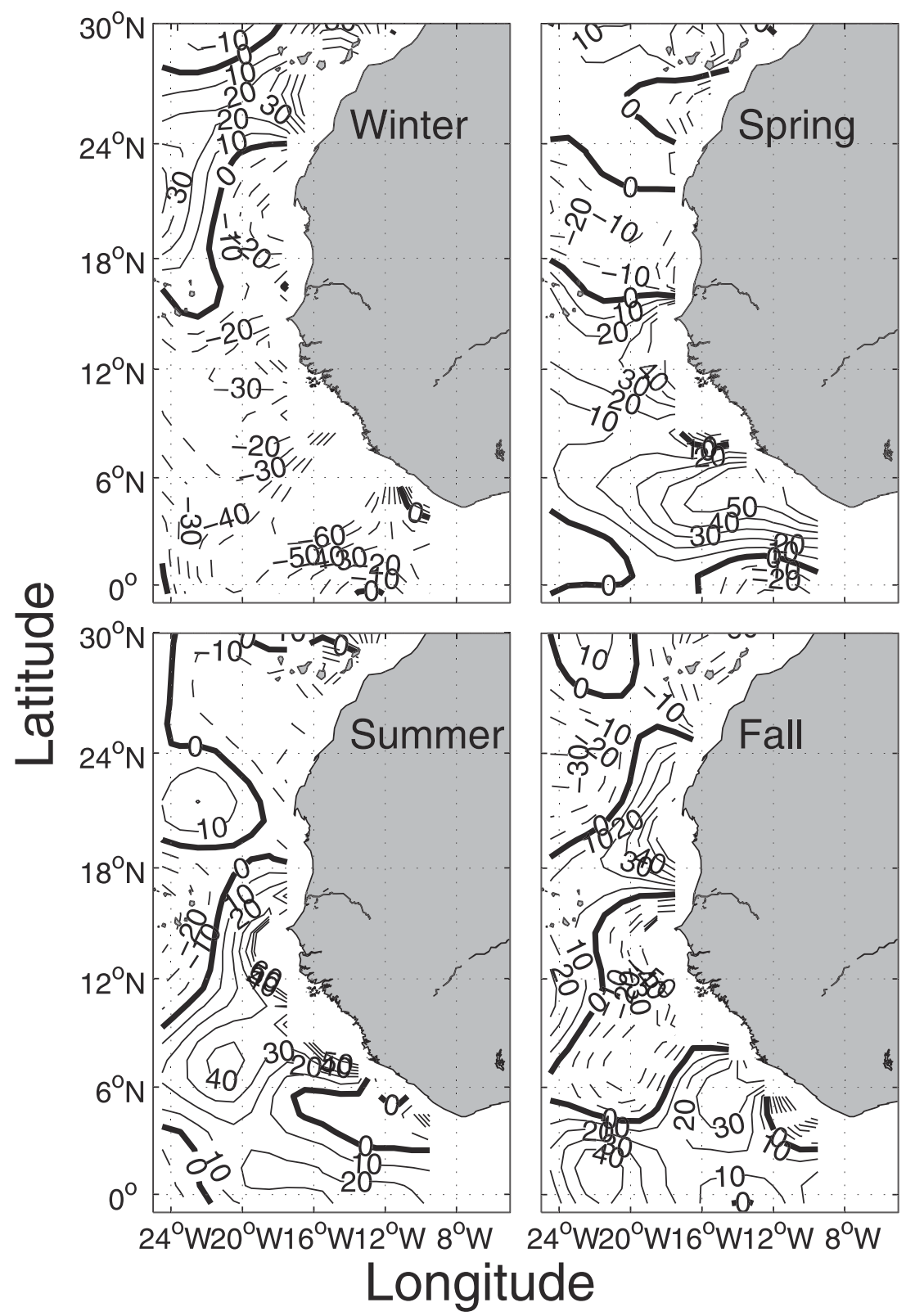

FIG. 11. Spatial distribution of changes in the depth of the $\gamma_{n}=27.3$ isoneutral (in $\mathrm{m}$, over 3 -month periods). Regions with negative values (dashed isolines) correspond to AAIWcolumn stretching.

with $v$ and $w$ the meridional and vertical velocity components, respectively; $f=2 \Omega \sin \theta$ is the Coriolis parameter; and $\beta=d f / d y$, where $\theta$ is the latitude and $y$ is the horizontal axis directed to the north. Equation (3) may be vertically integrated over any layer, such as that comprising the AAIW, to give

$$
\int_{-H}^{-h} v d z=\frac{f}{\beta}\left(w_{t}-\frac{d h}{d t}\right)
$$

where $z=-h$ and $-H$ are the depths of the upper and lower isoneutrals comprising the AAIW, $w_{t}$ is the dianeutral velocity at this upper isoneutral, and we have assumed that the lower interface is stationary and the dianeutral velocity there is negligible.

The last term in Eq. (4) contains local and advective terms. For our region and depths of interest, the meridional advective term is much greater than the zonal one, as $u \approx v$ and $\partial h / \partial y>>\partial h / \partial x$ (Kawase and Sarmiento 1985). Hence the material derivative is written as the 


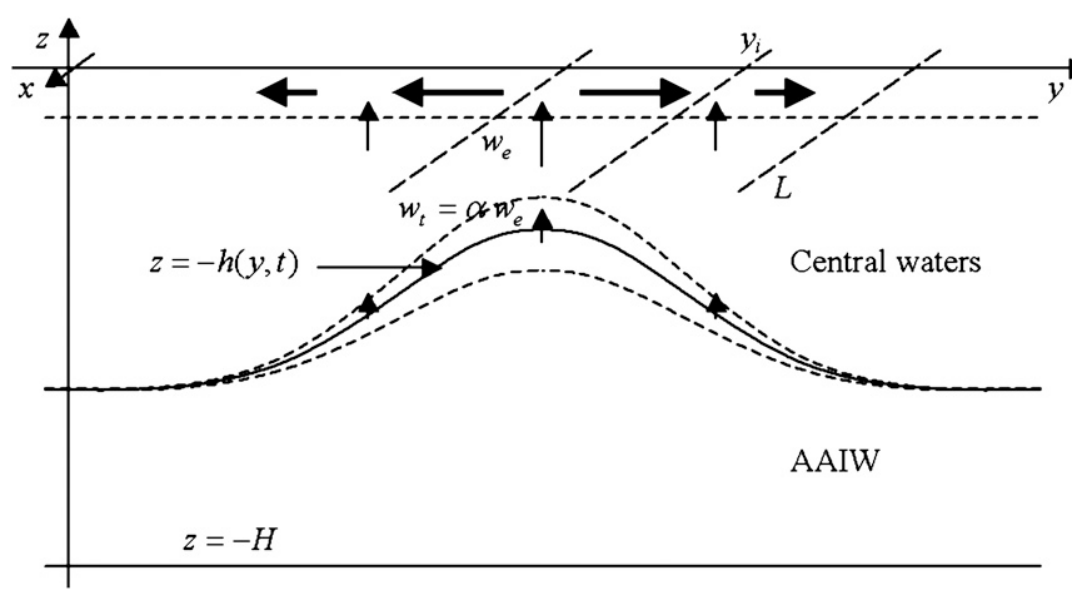

FIG. 12. Schematics of the main model elements.

sum of the local temporal rate and the meridional advective terms; that is, $d h / d t=\partial h / \partial t+v \partial h / \partial y$.

Although we recognize that the upper-ocean turbulence may have many sources, it appears reasonable to expect that a major contribution should arise as a result of surface wind forcing. Here we assume that the entrainment velocity $w_{t}$ at the upper bound of the intermediate water strata is proportional to the Ekman pumping velocity,

$$
w_{t}=\alpha w_{e}=\frac{\alpha}{\rho}\left[\frac{\partial}{\partial x}\left(\frac{\partial \tau_{y s}}{f}\right)-\frac{\partial}{\partial y}\left(\frac{\tau_{x s}}{f}\right)\right],
$$

where $\alpha<1$ is an efficiency coefficient that determines what fraction of the Ekman pumping velocity $w_{e}$ produces dianeutral transfer at $z=-h$, and $\left(\tau_{x s}, \tau_{y s}\right)$ are the horizontal components of the surface wind stress. Despite the limitations in this approach we expect it to indicate the potential importance of this term.

Finally, as our horizontal scale is much less than the earth's radius, the meridional transport per unit length becomes

$$
\int_{-H}^{-h} v d z=\frac{\alpha}{\beta \rho}\left(\frac{\partial \tau_{y s}}{\partial x}-\frac{\partial \tau_{x s}}{\partial y}\right)-\frac{f}{\beta} \frac{\partial h}{\partial t}-\frac{f}{\beta} v \frac{\partial h}{\partial y} .
$$

The horizontal distribution of each term in the righthand side of Eq. (6) is calculated using the seasonal hydrographic and surface wind stress climatologies (WOA01 and SOC databases), as explained in section 2 (Figs. 13, 14, and 15). For the first term we have chosen $\alpha=1$, as if all water pumped to the surface Ekman layer originates from intermediate waters. This is not the case (so that $\alpha<1$ ), but there may be other contributions to dianeutral mixing indirectly related to wind forcing, which could be parameterized through an increase in $\alpha$. This is an important limitation to keep in mind, but we will see below that even with $\alpha=1$, the dianeutral mixing term is not the dominant one.

To calculate the distributions of the second (Fig. 14) and third terms (Fig. 15), we have considered the temporal and meridional changes of the $\gamma_{n}=27.3$ isoneutral. The second term may be estimated using the seasonal changes in the depth of this isoneutral. These changes are calculated for the whole region over threemonth periods centered at February (winter), May (spring), August (summer), and November (fall). Positive values (solid lines) correspond to shallowing of the interface isoneutral; that is, to thickening of the AAIW stratum. To obtain the third term, however, we need the distribution of the meridional velocity on this isoneutral. We do not know this value but the 27.3 isoneutral corresponds to the interface between the southward-flowing NACW and the northward-flowing AAIW, so we anticipate it to be very small. Knoll et al. (2002) present velocity time series at $720 \mathrm{~m}$, near the depth of this isoneutral, in the channel between the Canary Islands and the African coast. Even in this location, where the flow should speed up as a result of the islands' channeling, these authors found that the mean velocity is $1.0 \pm 0.4 \mathrm{~cm} \mathrm{~s}^{-1}$. Further, Machín et al. (2006) applied an inverse model north of the Canary Islands to calculate that the reference velocity at these depths is less than $1 \mathrm{~cm} \mathrm{~s}^{-1}$. Hence, we have assumed a spatially constant northward velocity of $1 \mathrm{~cm} \mathrm{~s}^{-1}$, simply to assess the size of this last term.

The size of the three contributions (dianeutral mixing, local temporal-rate, and meridional advection) to the meridional transport of AAIW in the eastern North Atlantic indicates that the most important term is the 


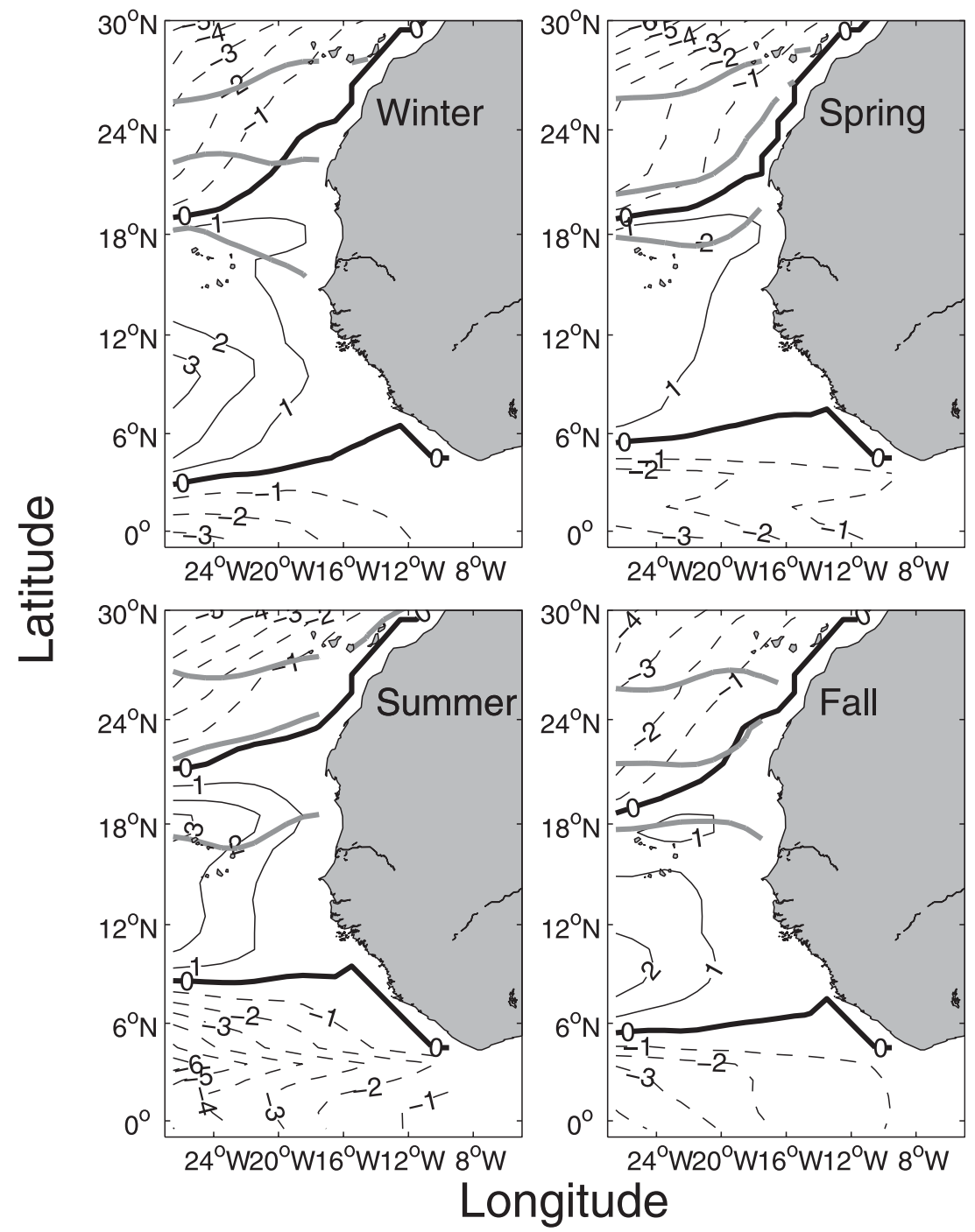

FIG. 13. Distribution of the dianeutral mixing term in Eq. (6) for $\alpha=1$, with seasonal wind stresses as obtained from the SOC climatological database. Selected isohalines are indicated in gray $(35.0,35.2,35.4)$.

local temporal rate. This term is typically twice as large as the dianeutral mixing term, while the meridional advection term is much smaller except in the northern portion of the domain. Therefore, we center our attention on the local temporal-rate term, by far the dominant one south of Cape Blanc. The spatial patterns of the seasonal stretching/shrinking term (Fig. 14) parallels the seasonal changes in the depth of the 27.3 isoneutral (Fig. 10), but weighted with the Coriolis parameter so that this term decreases substantially at low latitudes.

We integrate the dominant term in Eq. (6) over a zonal transect of length $L_{i}=L\left(y=y_{i}\right)$ in order to estimate the total meridional transport of AAIW at the latitude $y=y_{i}$. Defining $V_{i} \equiv \int_{L_{i}} \int_{-H}^{-h} v d z d x$, Eq. (6) becomes

$$
V_{i} \simeq-\frac{f}{\beta} \int_{L_{i}} \frac{\partial h}{\partial t} d x
$$

To estimate northward transport we must choose zonal transects $L_{i}$ in the eastern tropical North Atlantic, which approximately cover the AAIW forcing region. This region goes from the African coast to some offshore position that has to be specified. Inspired by Fig. 13 , we select this to be a constant longitude value of $23.5^{\circ} \mathrm{W}$, or a constant isohaline that delimits AAIW, whichever is found first. For example, when we increase the bounding isohaline from 35.0 to 35.2 and 35.4, the domain stretches roughly $5^{\circ}$ in latitude each time. With the idea of a winter forcing in the tropical region and northward progression throughout the seasons, we have 


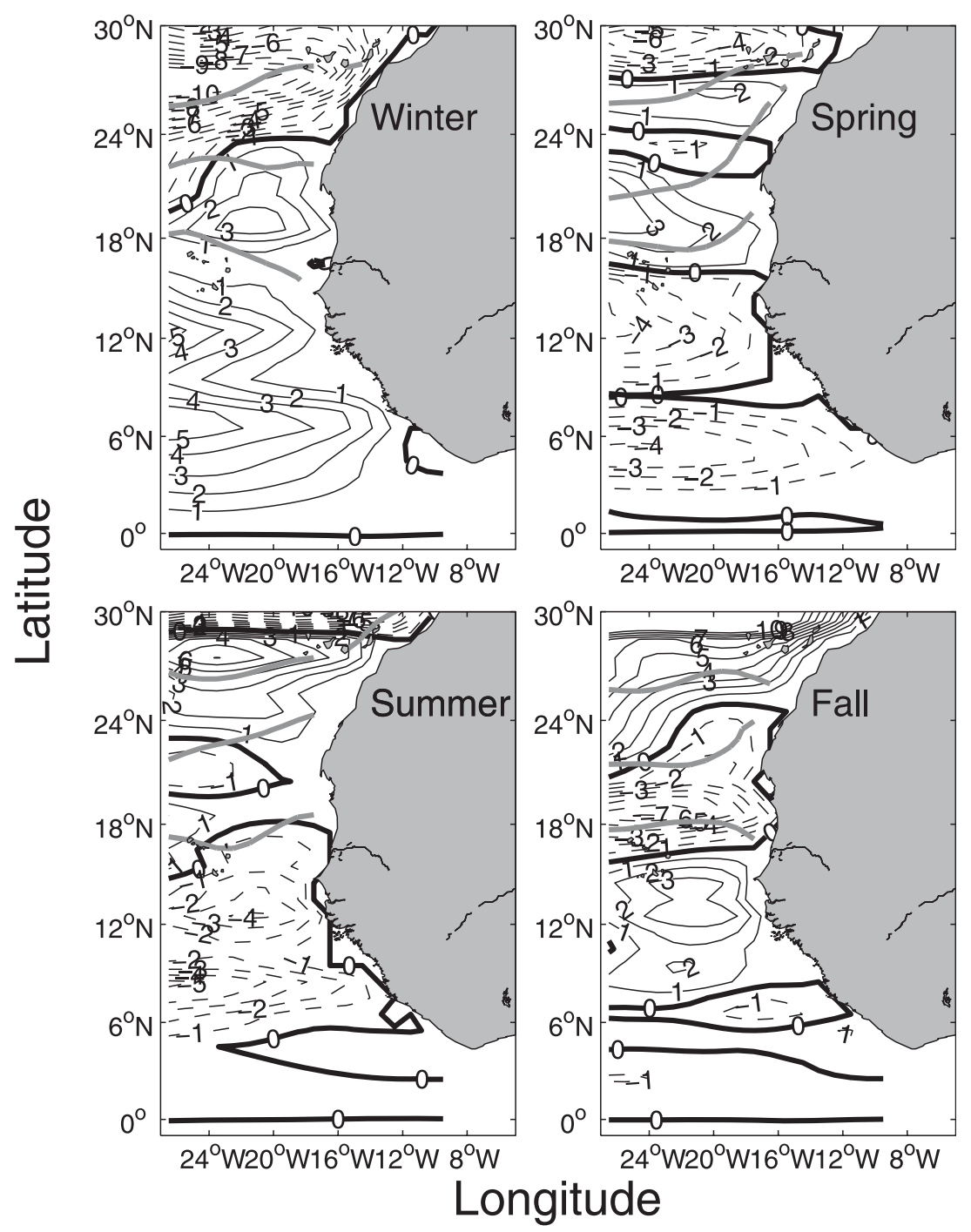

FIG. 14. Distribution of the seasonal shrinking-stretching term in Eq. (6) evaluated on $\gamma_{n}=27.3$. Selected isohalines are indicated in gray $(35.0,35.2,35.4)$.

selected this limiting isohaline as 35.0 for winter, 35.2 for spring, and 35.4 for summer. For fall we let the integration to continue farther north in a band of $2^{\circ}$ adjacent to the African coastline. At these high latitudes, the meridional advection term is about the same size as the local temporal-rate change, so in the fall we apply Eq. (7) replacing $\partial h / \partial t$ by $d h / d t$.

Figure 16 shows the meridional transports resulting from the zonal integration as explained above. During each season the maximum transport is between 2 and 4 $\mathrm{Sv}$ to the north. The latitude of this maximum transport actually shifts meridionally with season, from about $7^{\circ} \mathrm{N}$ in winter to $18^{\circ} \mathrm{N}$ in spring and $28^{\circ} \mathrm{N}$ in summer. These results suggest that the propagation of AAIW is associated to the seasonal lifting of the upper-thermocline iso- neutrals in the eastern equatorial and tropical Atlantic. An AAIW water column becomes progressively stretched as it travels north, parallel to the African coast, until reaching the Canary Islands about nine months later. This column may yet follow beyond the Canary Archipelago, thanks to the northward shallowing of the 27.3 isoneutral, which is enhanced in the fall. The rate of propagation suggested by Fig. 16 (approximately $11^{\circ}$ of latitude in nine months) corresponds to a feasible meridional velocity at the core of the AAIW of about $5 \mathrm{~cm} \mathrm{~s}^{-1}$.

\section{AAIW's ending}

Figure 16 shows that, during fall, AAIW is transported as far as the Canary Archipelago, in agreement 


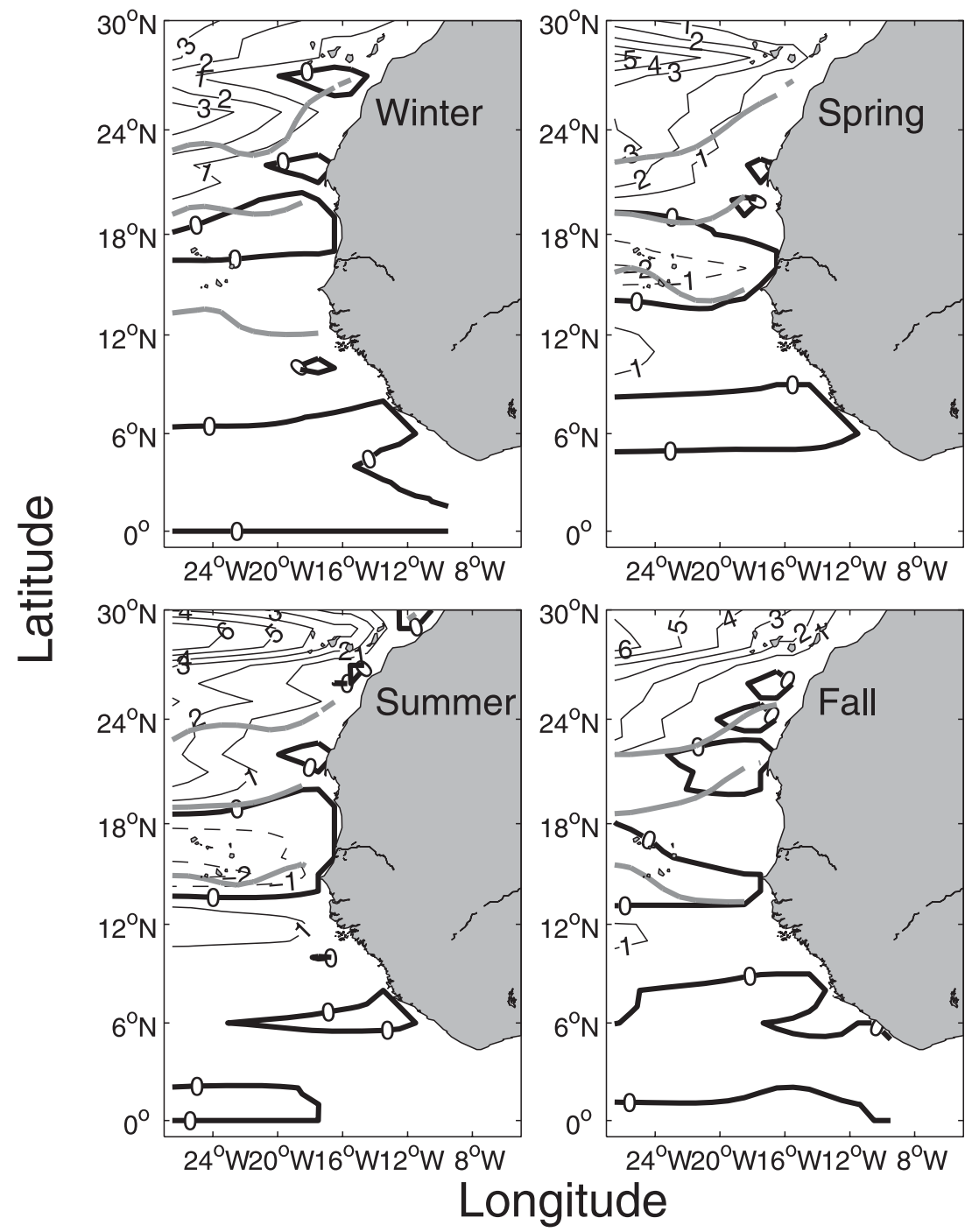

FIG. 15. Distribution of the seasonal isopycnal-sloping term in Eq. (6) evaluated on $\gamma_{n}=$ 27.3 , with a constant northward velocity $v=0.01 \mathrm{~m} \mathrm{~s}^{-1}$. Selected isohalines are indicated in gray $(35.0,35.2,35.4)$.

with our analysis of field data. It also agrees with Knoll et al. (2002) observations of a fall intensification of the AAIW northward flow through the channel between the eastern Canary Islands and the African coast. North of the Canary Archipelago this water has to be removed from this region, by either flowing west or mixing with the over and underlying strata. The climatological and hydrographic data do not evidence a mean westward path, so we have to explore the possibilities that the diluted AAIW is either diffused with the surrounding strata, mainly with the overlaying NACW, or that it is intermittently advected away from the eastern boundary region.

The first possibility is that the relative freshness and coolness of AAIW enhances the salt-finger favorable background situation in the North Atlantic, so that the salt and temperature anomalies are removed via the large effective dianeutral diffusion associated to this process (Schmitt et al. 2005). In Fig. 17 we have used the cross-shore sections during F91 and F92 to draw the Turner angle Tu (Ruddick 1983) on top the fraction of AAIW. Turner angles above $70^{\circ}$ indicate regions of strong double diffusion. We observe that these values take place in the upper portion of the AAIW stratum, in a $200-$ to $300-\mathrm{m}$ water column solely constituted by NACW and AAIW.

In Fig. 18 we have drawn, as an example, the vertical distribution of several variables for two stations in section F91-I, where AAIW is clearly dominant at about $800-\mathrm{m}$ depth. In these figures we again only plot the upper portion of the water column, where AAIW's 


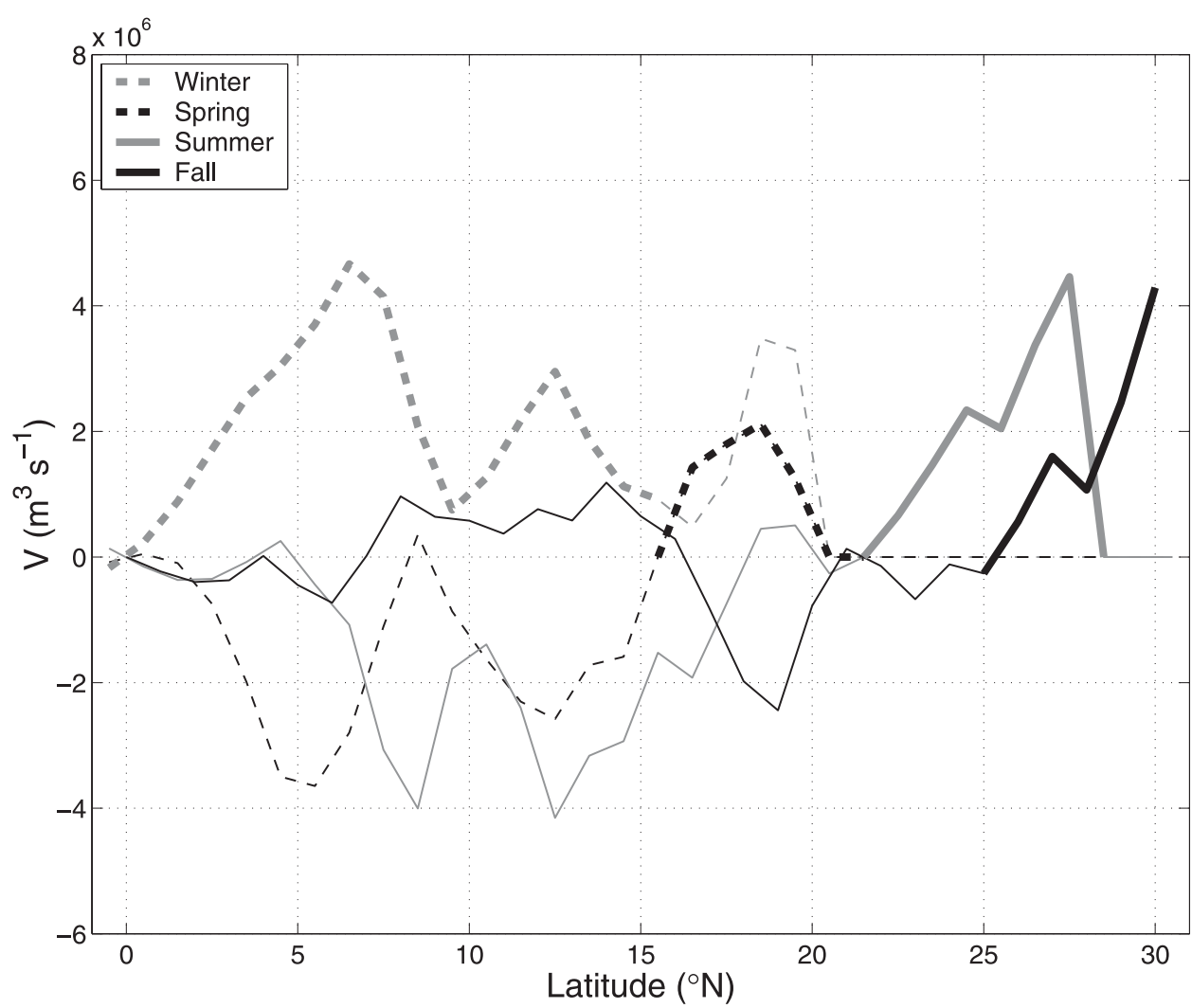

FIG. 16. Seasonal shrinking-stretching term evaluated on $\gamma_{n}=27.3$, integrated from the African coast to $23.5^{\circ} \mathrm{W}$, or until a selected constant isohaline (see text for explanations).

content (measured as the depth derivative of the AAIW contribution, $\partial x_{\mathrm{AAIW}} / \partial z$ ) decreases rapidly. Turner angles above $70^{\circ}$ are concurrent with maximum vertical gradients of the AAIW concentration, $x_{\text {AAIW }}$, hence supporting the potential role of this water mass to enhance dianeutral diffusion.

We may grossly estimate how long it would take for the central waters to dilute out the intermediate water signal, simply as $t=s^{2} / K$, where $h$ is the vertical thickness that has to be diluted, $K$ is the vertical diffusivity, and $s$ is a factor that depends on the fraction of NACW that replaces AAIW (e.g., Batchelor 1977, p. 190). Typical vertical diffusivities for the upper thermocline of the eastern subtropical gyre have been reported by Ledwell et al. (1998) to be $K \simeq 10^{-5} \mathrm{~m}^{2} \mathrm{~s}^{-1}$, but Schmitt et al. (2005) has found that double diffusion processes may increase this value to as much as $1 \mathrm{~m}^{2} \mathrm{~s}^{-1}$. Setting a $90 \%$ dilution $(s=30)$ over a layer of the thickness of the intermediate water stratum, $h=400 \mathrm{~m}$, and using an effective $K=1 \mathrm{~m}^{2} \mathrm{~s}^{-1}$, leads to a dilution time as short as two months. This supports the idea that double diffusion, in contrast to the background diffusion, may be a significant process in eroding away the AAIW anomalies at seasonal time scales.
A second possibility is that AAIW may be expulsed intermittently through its interaction with Mediterranean water lenses (Meddies). Between the Canary Archipelago and the Iberian Peninsula, off the African slope, we find that MW and AAIW occupy the intermediate water strata. This is actually a transition region from AAIW to MW (Fig. 3), where the two water masses display some meridional large-scale interleaving, with the former on top of the latter (Figs. 1 and 10). This is also a region where Meddies are commonly found (Armi et al. 1989; Fiekas et al. 1992; Müller and Siedler 1992; Siedler et al. 2005; Machín et al. 2006). These highly coherent structures have long lifetimes, typically over one year, and after moving in the Canary Basin they usually travel west. Armi et al. (1989), for example, reported a Meddy that moved $1000 \mathrm{~km}$ in $2 \mathrm{yr}$, or a mean speed of 1.6 $\mathrm{cm} \mathrm{s}^{-1}$. A plausible hypothesis is that a Meddy traveling through the region would have plenty of time to trap some of the overlying AAIW water, which would be taken away as it leaves the zone.

To explore the interaction of Meddies and AAIW, we have examined the ESTOC current meters located near the AAIW and MW cores (800 and $1200 \mathrm{~m}$, respectively). Meddies display positive salinity anomalies at 


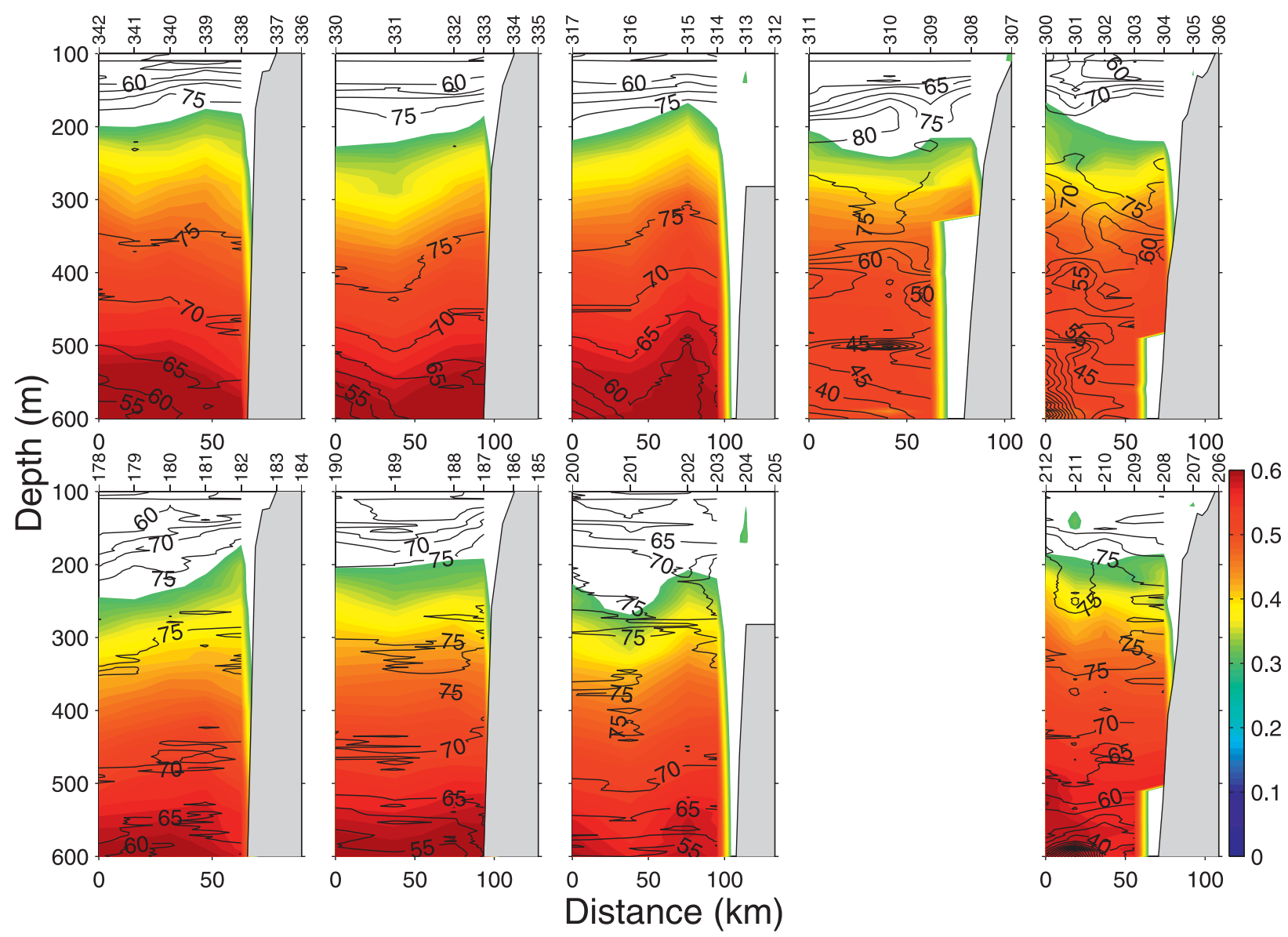

FIG. 17. Relative contribution of pure AAIW ( $X_{\text {AAIW }}$, colored) and Turner angle (Tu, contoured) during the (upper) F91 and (lower) F92 cruises, in transition depths from central to intermediate waters (see Figs. 2 and 9 for reference).

depths $\left(1000<z<1500 \mathrm{~m}, 27.6<\gamma_{n}<27.8\right)$ just under AAIW $\left(600<z<1000 \mathrm{~m}, 27.2<\gamma_{n}<27.65\right)$. The salinity time series shows that two Meddies passed by the mooring location on January-February 1995 (M1) and on December 1995-January 1996 (M2). The M2 made contact with the mooring twice within that period. Salinity at $1200 \mathrm{~m}$ during the Meddy occurrences increases to nearly 36.2 , much higher than climatological mean salinity at that depth (Fig. 19a). The velocity at both 800 and $1200 \mathrm{~m}$ vary in concert, alternating between periods of northward and southward flows. The most intense velocities throughout the entire record are associated with the appearance of the Meddies and approach $35 \mathrm{~cm} \mathrm{~s}^{-1}$ at $1200 \mathrm{~m}$, with the $800-\mathrm{m}$ velocity only slightly less intense during their passage (Fig. 19b).

Having identified these Meddies at $1200 \mathrm{~m}$, we look at the corresponding time series data at $800 \mathrm{~m}$ to investigate the properties of the overlying water column. The salinity at $800 \mathrm{~m}$ is generally within 0.045 of the mean climatological salinity at the site (Fig. 19a), except during the passage of the Meddies, when the salinity at
$800 \mathrm{~m}$ plunges by between 0.08 and 0.14 . The only additional anomalous event is the appearance of a thick salty anomaly in October-November 1995 concurrent with weak velocities, a feature apparently unrelated to a Meddy. The decrease in salinity at $800 \mathrm{~m}$ during the Meddies' passage indicates that the fresh anomaly has approximately the same spatial scale as the Meddy, and suggests that the water mass at this depth is composed by AAIW. In particular, during M1, the maximum change in salinity at $800 \mathrm{~m}$ arrives before the Meddy core at $1200 \mathrm{~m}$, suggesting it corresponds to the Meddy edge, where velocities are highest and maximum coupling between the Meddy and the overlying water is to be expected.

It could be argued that the salinity decrease was related to the deep salinity minimum in central waters. This would happen if an intense salinity minimum were located below the 800-m current meter and the Meddy's passage caused a large-enough vertical perturbation of the background salinity field. To discard this possibility we have constructed Fig. 19c, which shows that the 

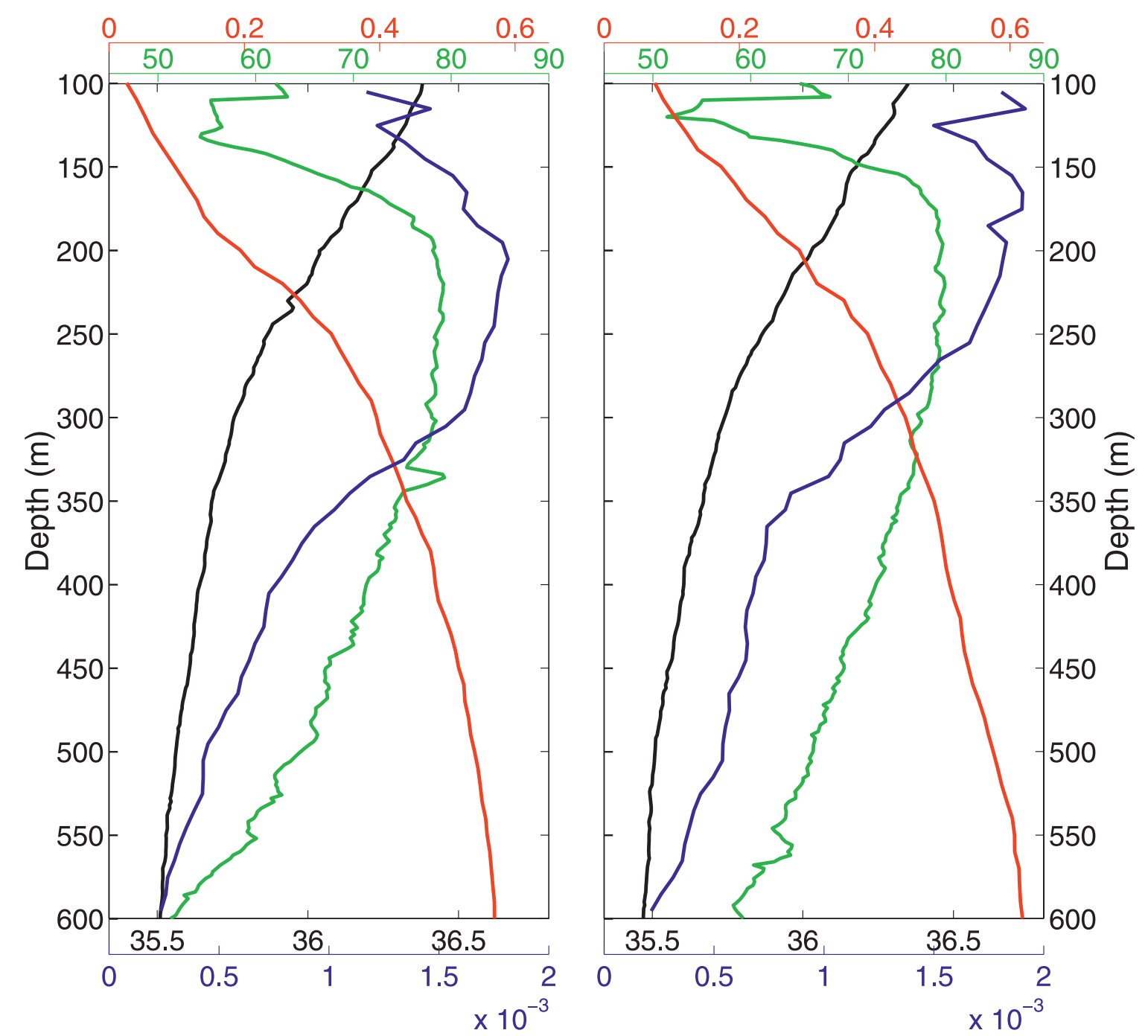

FIG. 18. Profiles of $S$ (black), Tu (green), contribution of AAIW to observations ( $x_{\text {AAIW }}$, red), and $\partial x_{\text {AAIW }} / \partial z$ (blue) at stations (left) 342 and (right) 340 of section F91-I (see Figs. 2, 9, and 17 for reference).

salinity minimum at the ESTOC location is found somewhere between 700 and $950 \mathrm{~m}$, with an average of $900 \mathrm{~m}$. However, the decrease in salinity detected at $800 \mathrm{~m}$ during the Meddy's passage (0.08 and 0.14 ) is greater than the standard deviation at the depth of the salinity minimum (0.06). Further, to get a change of 0.08 units in the mean salinity profile we have to go as shallow as $600 \mathrm{~m}$. Hence, it seems evident that the observed decrease in salinity at $800 \mathrm{~m}$ is indeed a real feature, related to the passage of a different water mass, a diluted AAIW.

\section{Conclusions}

We have detected the presence of AAIW along the African slope as far north as $34^{\circ} \mathrm{N}$ during the falls of 1991, 1992, 1995, and 1997. At these high latitudes,
AAIW is found to spread mainly in the 27.4-27.6 $\gamma_{n}$ stratum (roughly 650-to-1000-m-depth range), its core (minimum salinity) located on the 27.5 isoneutral (at about 800-m depth), though some intermediate water may be found as shallow as $\gamma_{n}=27.3$ (at about $500 \mathrm{~m}$ ). Figure 20 summarizes the spreading of AAIW off northwest Africa in the $27.4 \leq \gamma_{n} \leq 27.5$ range. During the fall cruises, AAIW reaches its northernmost extension, up to $33.5^{\circ}-34^{\circ} \mathrm{N}$, while during the 1992 winter cruise it is nearly undetectable in the domain, coinciding with a southward intrusion of MW.

A simple model suggests that the northward spreading of AAIW is remotely forced in the eastern North Atlantic tropical ocean. In this region, winter Ekman pumping becomes very intense and localized near the African coast. This raises the upper-ocean isoneutrals 

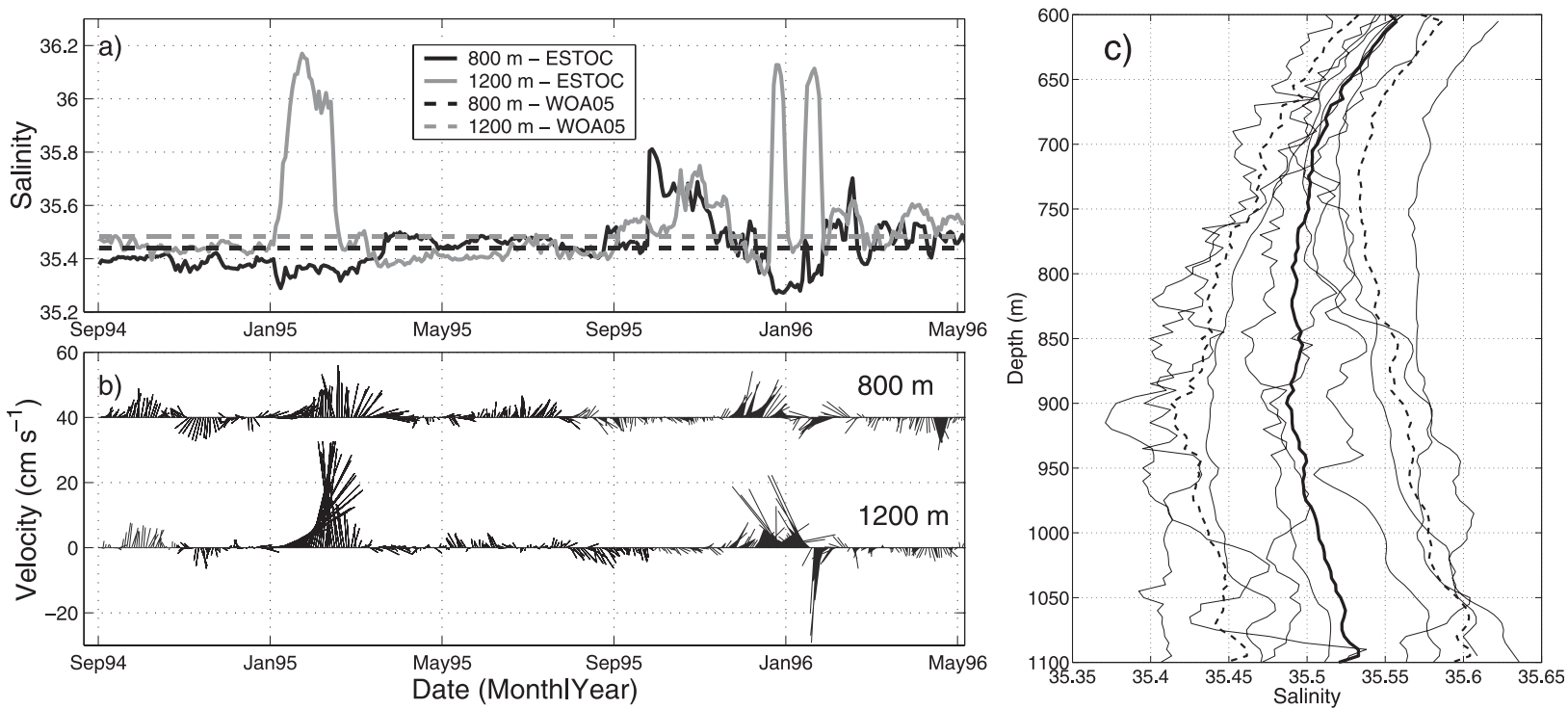

FIG. 19. (a) Salinity in ESTOC mooring at $800 \mathrm{~m}$ (black) and $1200 \mathrm{~m}$ (gray), from September 1994 to May 1996. Climatological salinity is drawn (dashed black and gray lines). (b) Velocity for the same depths and time period. Note that the origin is displaced to $40 \mathrm{~cm} \mathrm{~s} \mathrm{~s}^{-1}$ for the time series at 800-m depth. (c) Salinity depth profiles for eight hydrographic stations taken within less than $5 \mathrm{~nm}$ of ESTOC station. The mean (thick black) and one-standard deviation (dashed) profiles are shown.

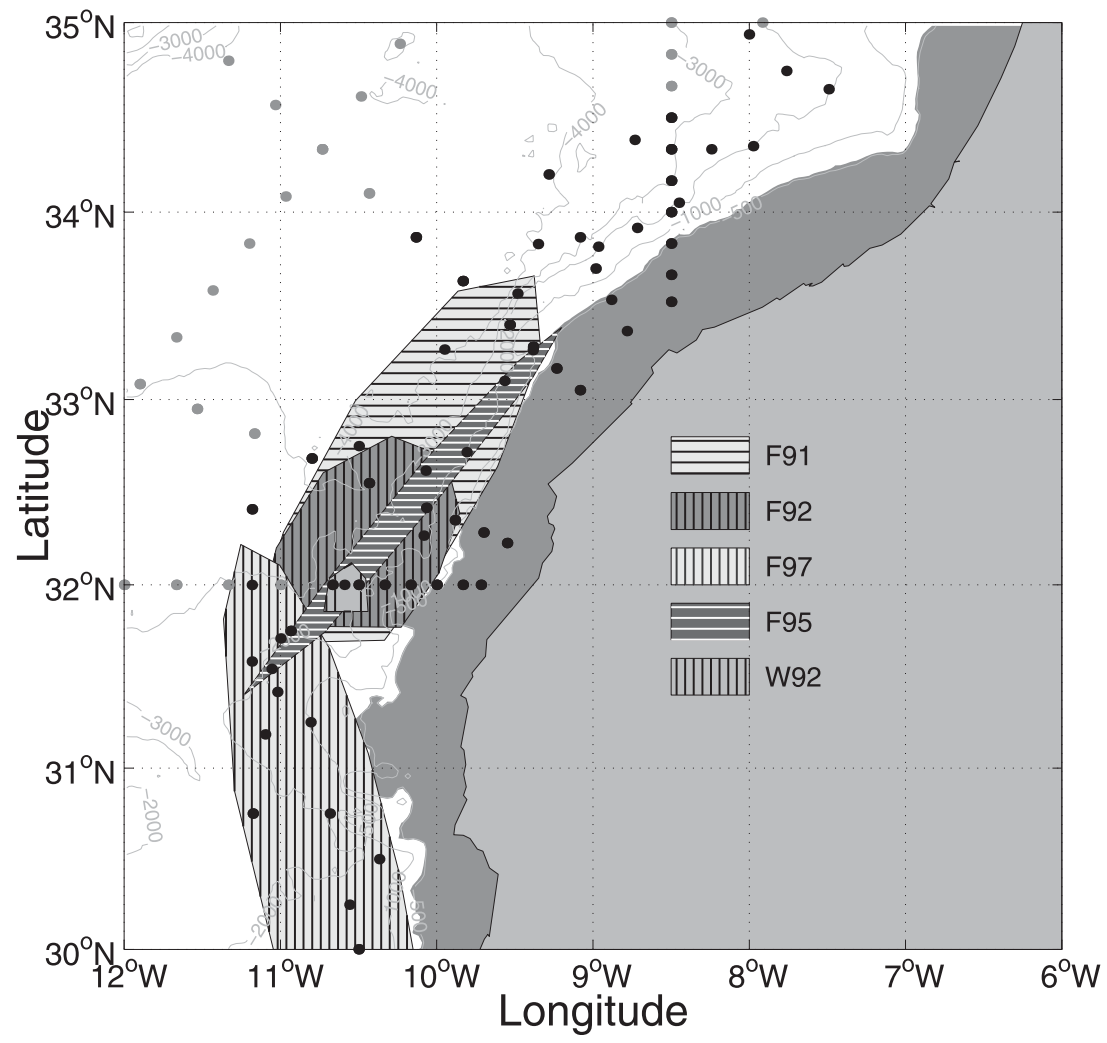

FIG. 20. Cartoon of AAIW's spreading during F91, F92, W92, F95, and F97 cruises. Depths shallower than $550 \mathrm{~m}$ are shaded in dark gray. Stations used in the study are drawn in black. 
and causes the AAIW water stratum to stretch. Conservation of potential vorticity implies that the intermediate stratum has to progress north along the eastern boundary during the subsequent months so that it reaches the Canary Archipelago by late summer. This seasonal progression is coherent with observations of a meridional displacement of the maximum northward transport, of about 3-4 Sv, associated to the stretching term. Beyond the Canary Archipelago, column stretching appears to be related to the northward shallowing of the isoneutral overlying the AAIW stratum. During fall, such shallowing may be reinforced by the central waters drawing a cyclonic gyre that encompasses the whole Canary Archipelago.

The rapid disappearance of AAIW north of the Canary Archipelago, observed to occur between September 1991 and January 1992, could partly result from a retreat of this water mass but may also be associated to the enhancement of double diffusion as a result of the intrusion of the relatively fresh intermediate water. This is supported by the coincidence of maximum Turner angles and the vertical gradient of the AAIW fraction. Another possibility, evidenced by mooring time series of salinity and current velocity, is intermittent AAIW export trough the interaction of this water stratum with underlying Meddies that move through the Canary Basin.

The observations here reported support that AAIW reaches its northernmost positions off northwest Africa during fall as part of a remotely forced intermediate depth eastern boundary current, and disappears during winter simultaneously with a sharp southward intrusion of MW. This is consistent with seasonal circulation patterns observed near the Canary Islands region (Knoll et al. 2002; Hernández-Guerra et al. 2003; Machín et al. 2006).

Acknowledgments. The first author has been funded by the Ministerio de Educación y Ciencia through the Juan de la Cierva Program. We are very grateful to our editor, Lynne Talley, and two anonymous reviewers for many useful comments and suggestions. We are also thankful to Jaime Palter for several useful discussions. We wish to thank the Woods Hole Oceanographic Institution and the U.S. National Oceanographic Data Center for making available the pre-WOCE, WOCE, and Hydrobase datasets. Funding for this work comes from the Ministerio de Educación y Ciencia, Spain, through Project CANOA (CTM2005-00444/MAR).

\section{REFERENCES}

Arhan, M., A. Colin de Vérdiere, and L. Mémery, 1994: The eastern boundary of the subtropical North Atlantic. J. Phys. Oceanogr., 24, 1295-1316.

Armi, L., D. Hebert, N. Oakey, J. Price, P. Richardson, H. Rossby, and B. Ruddinck, 1989: Two years in the life of a Mediterranean salt lens. J. Phys. Oceanogr., 19, 354-383.
Barton, E., 1989: The poleward undercurrent of the eastern boundary of the subtropical North Atlantic. Poleward Flows Along Eastern Ocean Boundaries, S. J. Neshyba et al., Eds., Vol. 34, Springer Verlag, 82-95.

Batchelor, G., 1977: An Introduction to Fluid Dynamics. Cambridge University Press, $615 \mathrm{pp}$.

Batteen, M., J. Martínez, D. Bryan, and E. J. Buch, 2000: A modeling study of the coastal eastern boundary current system off Iberia and Morocco. J. Geophys. Res., 105C, 14 17314195.

— A. Martinho, H. Miller, and J. McClean, 2007: A processoriented modelling study of the coastal Canary and Iberian Current system. Ocean Modell., 18, 1-36.

Broecker, W. S., and T. Takahashi, 1981: Hydrography of the central Atlantic-IV. Intermediate waters of Antarctic origin. Deep-Sea Res., 28, 177-193.

Castro, C., F. Pérez, S. Holley, and A. Ríos, 1998: Chemical characterization and modelling of water masses in the Northeast Atlantic. Prog. Oceanogr., 41, 249-279.

Elmoussaoui, A., M. Arhan, and A. Treguier, 2005: Modelinferred upper ocean circulation in the eastern tropics of the North Atlantic. Deep-Sea Res. I, 52, 1093-1120.

Fiekas, V., J. Elken, T. Müller, A. Aitsam, and W. Zenk, 1992: A view of the Canary Basin thermocline circulation in winter. $J$. Geophys. Res., 97C, 12 495-12 510.

Fratantoni, D., and P. Richardson, 1999: SOFAR float observations of an intermediate-depth Eastern Boundary Current and mesoscale variability in the eastern tropical Atlantic Ocean. $J$. Phys. Oceanogr., 29, 1265-1278.

— W. Wohns, and T. Townsend, 2000: Low-latitude circulation and mass transport pathways in a model of the tropical Atlantic ocean. J. Phys. Oceanogr., 30, 1944-1966.

Hernández-Guerra, A., and Coauthors, 2003: Transport variability in the Lanzarote Passage (Eastern Boundary Current of the North Atlantic Subtropical Gyre). Deep-Sea Res. I, 50, 189-200.

— , F. López-Laatzen, F. Machín, D. de Armas, and J. Pelegrí, 2001: Water masses, circulation and transport in the Eastern Boundary Current of the North Atlantic Subtropical Gyre. Sci. Mar., 65 (Suppl. I), 177-186.

Iorga, M., and M. S. Lozier, 1999: Signatures of the Mediterranean outflow from a North Atlantic climatology. 1. Salinity and density fields. J. Geophys. Res., 104C, 25 985-26 009.

Johnson, J., and I. Stevens, 2000: A fine resolution model of the eastern North Atlantic between the Azores, the Canary Islands and Gibraltar Strait. Deep-Sea Res. I, 47, 875-899.

Kawase, M., and J. Sarmiento, 1985: Nutrients in the Atlantic thermocline. J. Geophys. Res., 90, 8961-8979.

Knoll, M., and Coauthors, 2002: The Eastern Boundary Current system between the Canary Islands and the African Coast. Deep-Sea Res. II, 49, 3427-3440.

Ledwell, J., A. Watson, and C. Law, 1998: Mixing of a tracer in the pycnocline. J. Geophys. Res., 103C, 21 499-21 529.

Longhurst, A., 1993: Seasonal cooling and blooming in tropical oceans. Deep-Sea Res. I, 40, 2145-2165.

Lozier, M. S., W. B. Owens, and R. Curry, 1995: The climatology of the North Atlantic. Prog. Oceanogr., 36, 1-44.

Luyten, J., J. Pedlosky, and H. Stommel, 1983: The ventilated thermocline. J. Phys. Oceanogr., 13, 292-309.

Machín, F., A. Hernández-Guerra, and J. L. Pelegrí, 2006: Mass fluxes in the Canary Basin. Prog. Oceanogr., 70, 416-447.

McClain, C., and J. Firestone, 1993: An investigation of Ekman upwelling in the North Atlantic. J. Geophys. Res., 98C, $12327-12339$ 
Mittelstaedt, E., 1983: The upwelling area off Northwest AfricaA description of phenomena related to coastal upwelling. Prog. Oceanogr., 12, 307-331.

Müller, T., and G. Siedler, 1992: Multi-year current time series in the eastern North Atlantic Ocean. J. Mar. Res., 50, 63-98.

Navarro-Pérez, E., and E. Barton, 2001: Seasonal and interannual variability of the Canary Current. Sci. Mar., 65 (Suppl. I), 205-213.

Paillet, J., and H. Mercier, 1997: An inverse model of the eastern North Atlantic general circulation and thermocline ventilation. Deep-Sea Res. I, 44, 1293-1328.

Parrilla, G., S. Neuer, P.-Y. Le Traon, and E. Fernández-Suárez, 2002a: Topical studies in oceanography: Canary Islands Azores Gibraltar Observations (CANIGO). Volume 1: Studies in the northern Canary Islands basin. Deep-Sea Res. II, 49, 3409-3413.

$\_, \ldots, \ldots$, and $\_$, 2002b: Topical studies in oceanography: Canary Islands Azores Gibraltar Observations (CANIGO). Volume 2: Studies of the Azores and Gibraltar regions. Deep-Sea Res. II, 49, 3951-3955.

Pedlosky, J., 1983: Eastern boundary ventilation and the structure of the thermocline. J. Phys. Oceanogr., 13, 2038-2044.

- 1987: An inertial theory of the Equatorial Undercurrent. $J$. Phys. Oceanogr., 17, 1978-1985.

Pelegrí, J. L., and Coauthors, 2005a: Coupling between the open ocean and the coastal upwelling region off Northwest Africa: Water recirculation and offshore pumping of organic matter. J. Mar. Syst., 54, 3-37.

_- and Coauthors, 2005b: Hydrographic cruises off northwest Africa: The Canary Current and the Cape Ghir region. J. Mar. Syst., 54, 39-63.

_ A. Marrero-Díaz, and A. W. Ratsimandresy, 2006: Nutrient irrigation of the North Atlantic. Prog. Oceanogr., 70, 366-406.

Pérez, F., and Coauthors, 2001: Mixing analysis of nutrients, oxygen and inorganic carbon in the Canary Islands region. J. Mar. Syst., 28, 183-201.

Peterson, R., and L. Stramma, 1991: Upper-level circulation in the South Atlantic. Prog. Oceanogr., 26, 1-73.

Reid, J., 1994: On the total geostrophic circulation of the North Atlantic Ocean: Flow patterns, tracers and transports. Prog. Oceanogr., 33, 1-92.
Richardson, P., and D. Walsh, 1986: Mapping climatological seasonal variations of surface currents in the tropical Atlantic using ship drifts. J. Geophys. Res., 91, 10 537-10 550.

Ruddick, B., 1983: A practical indicator of the stability of the water column to double-diffusive activity. Deep-Sea Res., 30, 1105-1107.

Schmid, C., G. Siedler, and W. Zenk, 2000: Dynamics of intermediate water circulation in the subtropical South Atlantic. $J$. Phys. Oceanogr., 30, 3191-3211.

Schmitt, R. W., J. R. Ledwell, E. T. Montgomery, K. L. Polzin, and J. M. Toole, 2005: Enhanced diapycnal mixing by salt fingers in the thermocline of the tropical Atlantic. Science, 308, 685-688.

Siedler, G., N. Zangenberg, R. Onken, and A. Morliére, 1992: Seasonal changes in the tropical Atlantic circulation: Observation and simulation of the Guinea Dome. J. Geophys. Res., 97, 703-715.

— L. L. Armi, and T. Muller, 2005: Meddies and decadal changes at the Azores Front from 1980 to 2000. Deep-Sea Res. II, 52, 583-604.

Signorini, S. R., R. G. Murtugudde, C. R. McClain, J. R. Christian, J. Picaut, and A. J. Busalacchi, 1999: Biological and physical signatures in the tropical and subtropical Atlantic. J. Geophys. Res., 104C, 18 367-18 382.

Stramma, L., and F. Schott, 1999: The mean flow field of the tropical Atlantic Ocean. Deep-Sea Res. II, 46, 279-303.

_ , S. Hüttl, and J. Schafstall, 2005: Water masses and current in the upper tropical northeast Atlantic off Northwest Africa. $J$. Geophys. Res., 110, C12006, doi:10.1029/2005JC002939.

Tsuchiya, M., 1989: Circulation of the AAIW in the North Atlantic Ocean. J. Mar. Res., 47, 747-755.

_- L. Talley, and M. McCartney, 1992: An eastern Atlantic section from Iceland southward across the Equator. Deep-Sea Res., 39, 1885-1917.

Wüst, G., 1935: Schichtung und Zirkulation des Atlantischen Ozeans. Die Stratosphäre. Wissenschaftliche Ergebnisse der Deutchen Atlantischen Expedition auf dem Forschung-und Vermessungsschiff Meteor 1925-1927, Vol. 6, 109-288.

Zenk, W., B. Klein, and M. Schröder, 1991: Cape Verde frontal zone. Deep-Sea Res., 38 (Suppl.1), 505-530. 